\title{
Combination Nanotherapeutics for Dry Eye Disease Treatment in a Rabbit Model
}

\author{
Liandi Huang ${ }^{1,2}$ \\ Huanhuan $\mathrm{Gao}^{3}$ \\ Zhigang Wang $\mathbb{1}^{2,4}$ \\ Yixin Zhong ${ }^{5}$ \\ Lan $\mathrm{Hao}^{4}$ \\ Zhiyu Du'
}

'Department of Ophthalmology, Second Affiliated Hospital of Chongqing Medical University, Chongqing, 400010, People's

Republic of China; ${ }^{2}$ State Key Laboratory of Ultrasound in Medicine and

Engineering, Second Affiliated Hospital of Chongqing Medical University,

Chongqing, 400010, People's Republic of

China; ${ }^{3}$ Department of Ophthalmology,

Third Affiliated Hospital of Chongqing

Medical University, Chongqing, 4000I0,

People's Republic of China; ${ }^{4}$ Chongqing

Key Laboratory of Ultrasound Molecular Imaging, Second Affiliated Hospital of

Chongqing Medical University,

Chongqing, 400010, People's Republic of

China; ${ }^{5}$ Department of Radiology, Second

Affiliated Hospital of Chongqing Medical

University, Chongqing, 4000I0, People's

Republic of China
Correspondence: Zhiyu Du

Department of Ophthalmology, Second

Affiliated Hospital of Chongqing Medical

University, Chongqing, People's Republic of China

Email duzhiyu@hospital.cqmu.edu.cn
Purpose: Anti-inflammation is essential for dry eye disease. Traditional anti-inflammation agent corticosteroids applied in dry eye disease (DED) treatment could result in high intraocular pressure, especially in long-term treatment. Thus, we have prepared a liposome loading 1-bromoheptadecafluorooctane and tetrandrine (PFOB@LIP-Tet) to treat DED via anti-inflammation that hardly affects intraocular pressure in this study, which provided another therapy strategy for dry eye disease.

Methods: We firstly detected the physicochemical properties of PFOB@LIP-Tet. Next, we tested the biosafety of synthesized liposomes for corneal epithelium. Then, we explored the accumulations and distribution of PFOB@LIP-Tet both in cellular and animal models. And then, we assessed the therapeutic effects of PFOB@LIP-Tet formulations by laboratory and clinical examinations. Last, we examined the changes in eye pressure before and after treatment.

Results: PFOB@LIP-Tet and Tet showed a characteristic absorption peak at $282 \mathrm{~nm}$ while PFOB@LIP did not. Large amounts of PFOB@LIP-Tet remained on the ocular surface and accumulated in the corneal epithelial cells in DED rabbits. Corneal staining scores of DED rabbits respectively treated by ATS, PFOB@LIP-ATS, Tet-ATS and PFOB@LIP-Tet-ATS for seven days were $3.7 \pm 0.5,3.2 \pm 0.4,1.5 \pm 0.5$ and $0.5 \pm 0.5$. The expressions of related cytokines were correspondingly downregulated significantly, indicating that the inflammation of DED was successfully suppressed. The intraocular pressure changes of DED rabbits before and after treatment by PFOB@LIP-Tet showed no statistical significance.

Conclusion: We successfully synthesized PFOB@LIP-Tet, and it could effectively treat dry eye disease via anti-inflammation but hardly affected the intraocular pressure.

Keywords: tetrandrine, inflammation, liposomes, dry eye disease

\section{Introduction}

Dry eye is a multifactor-induced disease accompanied by increased osmolarity of the tear film and inflammation of the ocular surface. ${ }^{1}$ The pain, irritative symptoms, and burden on visual function resulting from dry eye disease have been disturbing the daily lives of adults of all ages around the world, ${ }^{2}$ especially women (female to male ratio nine to one) and elders, ${ }^{3,4}$ and could reduce their work productivity. ${ }^{5}$ The present main therapeutic strategies for DED include topical tear substitutes and lubrication, anti-inflammation, secretagogue, punctual occlusion, autologous serum, mucolysis and therapeutic contact lenses, and management of eyelid. ${ }^{6}$ Among them, artificial tear substitutes (ATS) is primarily and most often used for its functions of lubrication and evaporation alleviation with few side effects regardless of the severity of the disease. ${ }^{7}$ Inflammation plays an important role in the genesis 
and development of dry eye disease, therefore, anti-inflammation is essential for dry eye disease treatment. ${ }^{8}$ Topical anti-inflammation agents such as corticosteroids could break the cycle of surface damage, and therefore could significantly improve the symptoms and clinical signs of moderate to severe dry eye disease, ${ }^{9}$ but the attendant complications such as increasing ocular pressure and cataract formation limit its use, especially for long-term application, ${ }^{10}$ so an effective anti-inflammatory agent with less impact on intraocular pressure is urgently needed for DED therapy.

Tetrandrine $\left(6,6^{\prime}, 7,12\right.$-tetramethoxy-2,2'-dimethyl-berbaman, Tet), a plant alkaloid extracted from a Chinese traditional herb Han-fang-chi, is initially used to treat hypertension, rheumatoid arthritis and pulmonary fibrosis. ${ }^{11-14}$ As research moves along, other bioactivities of Tet including inducing cancer cells apoptosis, ${ }^{15}$ reversing drug resistance in cancer therapy, ${ }^{16}$ anti-oxidizing ${ }^{17}$ and suppressing inflammation ${ }^{18}$ have been gradually found. In ophthalmology, its therapeutic functions on conjunctivitis, ${ }^{19}$ ocular hypertension, ${ }^{20}$ Haze $^{21}$ and uveitis $^{22}$ have also been explored. Liposomes are artificial spherical vesicles consisting of one or more phospholipid bilayers with inner aqueous lumen from the external aqueous environment, ${ }^{23}$ which resemble cell membrane, and have been studied as drug carriers for both water and liquid-soluble agents since 1970 s. ${ }^{24,25}$ In ophthalmology, they have been widely studied for drug delivery not only due to their complete biodegradability and relative nontoxicity in preparations, ${ }^{26,27}$ but also for prolonging the action time of encapsulated drugs by controlling release. ${ }^{28}$ In addition it has been found that chemical modification such as cationization could provide greater duration of action and higher drug delivery on the cornea for liposomes. $^{29}$ But for DED, tear secretion is seriously decreased and barrier function of tear film is unavoidably damaged, ${ }^{1}$ which we supposed would be convenient for conventional liposomes to reside on the ocular surface, so we planned to adopt a conventional liposome for this study. 1-Bromoheptadecafluorooctane (PFOB) is a soluble phase-change material used in PLV to improve oxygenation and pulmonary function in acute lung damage administration. ${ }^{30}$ As the study develops in depth, it has been found that PFOB could target the epithelium and locate inflammation in the injured region. ${ }^{31}$ We hypothesized that anti-inflammation activation of Tet would be increased combined with PFOB loading on liposomes, and effectively treat dry eye disease via anti-inflammation.

\section{Materials and Methods}

Dipalmitoyl phosphatidyl ethanolamine (DPPE) was obtained from Corden (Liestal, Switzerland). Cholesterol was purchased from Ruixi Biological Technology (Xi'an, China). Soybean lecithin and benzalkonium chloride were supplied by Macklin (Shanghai, China). Lipopolysaccharide (LPS) and 1-bromoheptadecafluorooctane (PFOB, 99\%) were purchased from Sigma-Aldrich Co. (St Louis, MO, USAa). Tetrandrine (Tet, 99\%) was purchased from Shanchuan Biotechnology (Xi'an, China). Artificial tear substitute (ATS) was purchased from Allergan Inc. (Irvine, CA, USA). PEG ${ }_{2}$, IL-1 $\beta$, VEGF and TNF- $\alpha$ ELISA kits were purchased from Fine Biotech (Wuhan, China). DAPI, 1,1'-dioctadecyl3,3,3',3'-tetramethylindocarbocyanine perchlorate (DiI), and 1,1-dioctadecyl-3,3,3,3-tetramethylindocarbocyanine iodide (DiR) were provided by Beyotime (Shanghai, China).

\section{Synthesis of Liposomes}

PFOB@LIP-Tet was synthesized through traditional film dispersion ultrasonic oscillation method ${ }^{32}$ (Figure 1): soybean lecithin: DPPE: cholesterol: Tet=7:1:2:6, $16 \mathrm{mg}$ in total, dissolved evenly in trichloromethane, then evaporated reelingly in a rotary evaporator $\left(50^{\circ} \mathrm{C}, 120 \mathrm{rpm} /\right.$ min) until a uniform thin liquid film formed. Next it was dissolved with PBS, then PFOB $(100 \mu \mathrm{L})$ was added. Finally, PFOB@LIP-Tet was obtained by ultrasound oscillation (55W, four minutes) with a sonicator (Sonics, USA) in an ice bath, and then centrifugation was performed at $6000 \mathrm{rpm} / \mathrm{min}$. Supernatants were removed and sediments were collected and resuspended by PBS or artificial tear substitutes.

\section{Observations of Physicochemical Properties of Liposomes}

The absorbance spectra of free Tet, PFOB@LIP and PFOB@LIP-Tet were detected by a UV spectrophotometer (UV2600, Shimadzu, Japan). The morphology of PFOB@LIP-Tet and PFOB@LIP were observed under transmission electron microscopy (TEM). Average size, polydispersion index (PDI), and surface potential were detected by a Malvern particle size analyzer. The mean size of PFOB@LIP-Tet were detected with prolonged time duration (1, 2, 3, 4, 5, 6, and 7 days). In addition, the gross appearance differences were recorded by digital photograph. 


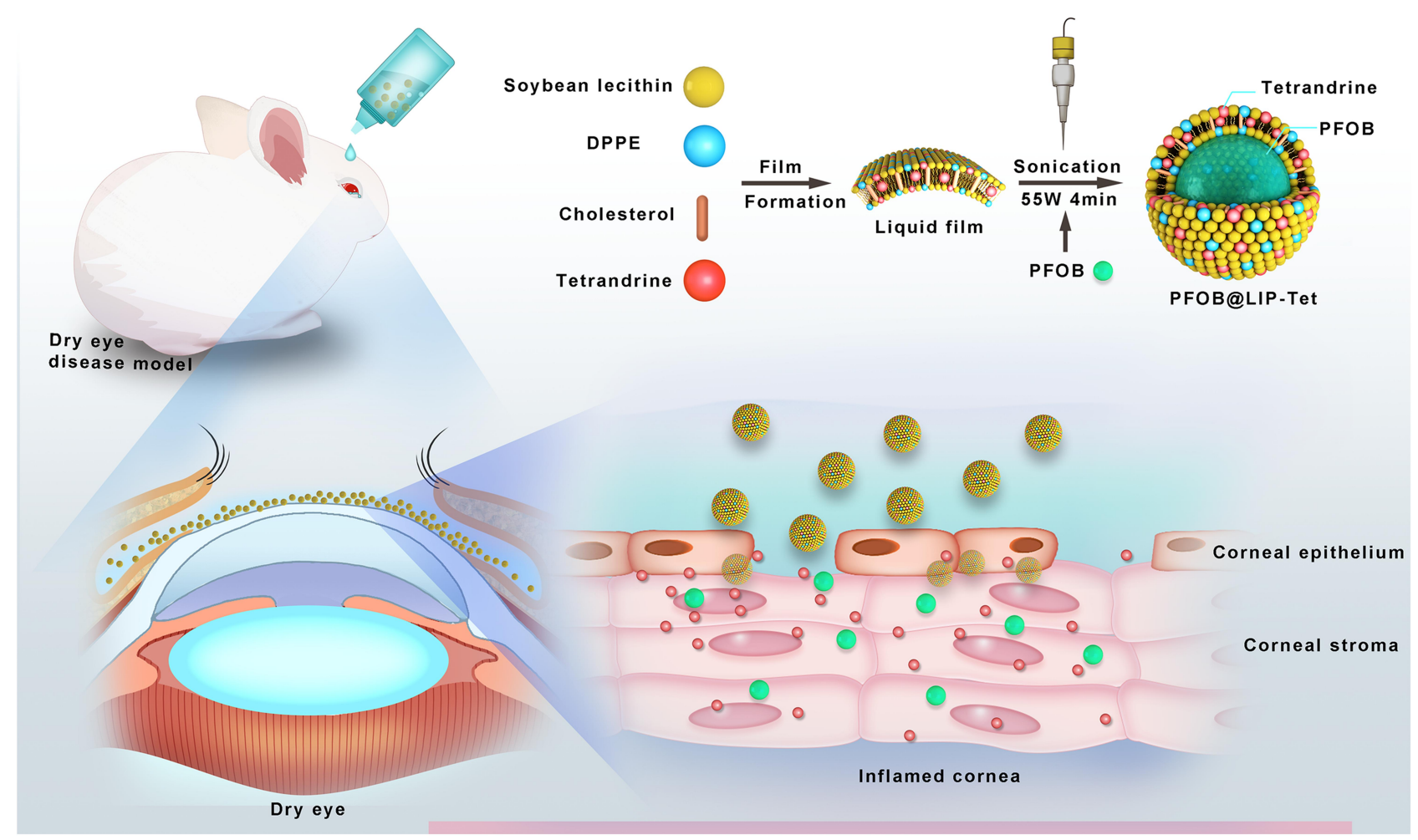

Figure I Schematic illustration of the synthesis of PFOB@LIP-Tet and the therapeutic process.

\section{Examinations of Tet Loading in Liposomes and Its Release Pattern}

The standard curve of Tet (dissolved in methyl alcohol) was established with an UV-vis-NIR spectrophotometer at the wavelength of $282 \mathrm{~nm}$. The encapsulation efficiency (EE) and loading capacity (LC) of Tet were determined by examining the content of Tet in the supernatant based on the corresponding absorbance of UV-spectrum at $282 \mathrm{~nm}$. $\mathrm{EE}$ and LC were calculated according to the formulas: $\mathrm{EE}$ $\%=$ weight of free Tet entrapped the liposomes/total weight of Tet, LC\%=weight of free Tet entrapped the liposomes/ weight of liposomes.

Drug release performance of Tet was determined in a dialysis bag in buffer solution (methyl alcohol, $99.99 \%$ ) at $4^{\circ} \mathrm{C}$ (storage temperature), $25^{\circ} \mathrm{C}$ (room temperature) and $33^{\circ} \mathrm{C}$ (corneal temperature). Briefly, $2 \mathrm{~mL}$ of PFOB@LIP-Tet-ATS suspension in a dialysis bag (MWCO:8000 Da) immersed in $50 \mathrm{~mL}$ of a buffer solution with stirring rate at $160 \mathrm{rpm}$ for $20 \mathrm{~h}$. At specific time intervals, $1 \mathrm{~mL}$ of determining concentrations of Tet was replaced with an equal volume of fresh methyl alcohol. Then the cumulative release amount of Tet was calculated with high-performance liquid chromatography (HPLC, VP-ODS $150 \mathrm{~mm} * 4.6 \mathrm{~mm}$, flow rate: $1 \mathrm{~mL} / \mathrm{min}$, mobile phase: methyl alcohol: water: triethyl amine $=750: 250: 0.5$ ) according to the standard curve.

\section{Cell Culture and Establishment of Animal Model}

Statens Seruminstitut rabbit corneal (SIRC) epithelial cells line was provided by Procell (Wuhan, China), and cultured with DMEM (Gibco, USA) medium containing 10\% FBS (EVERY GREEN, China) and 1\% penicillin-streptomycin and incubated under a $5 \% \mathrm{CO}_{2}$ atmosphere at $37^{\circ} \mathrm{C}$.

Thirty-five New Zealand White rabbits (purchased from and nursed at Chongqing Medical University Animal Research Center) weighing from $2.0 \mathrm{~kg}$ to $2.5 \mathrm{~kg}$ were used for this study. All rabbits were quarantined and acclimatized for a week at the Animal Research Center of Chongqing Medical University before the experiments. The left eye of 28 rabbits was treated with $0.1 \%$ BAC, $40 \mathrm{uL}$ topically, three times a day for 14 days. ${ }^{33}$ The DED models in rabbits were established seriously subject to guideline of Animal Ethics Committee and approved by 
Animal Ethics Committee of Chongqing Medical University. Then all rabbits were randomly divided into four equal groups, including ATS group, Tet-ATS group, PFOB@LIP-ATS group and PFOB@LIP-Tet-ATS group. The remaining seven rabbits without BAC applied to their left eye was the normal (control) group. All operations on cells and animals were approved by the Animal Ethics Committee of Chongqing Medical University.

\section{Biosafety of Tet and PFOB@LIP-Tet}

Toxicity of Tet and PFOB@LIP-Tet were detected by Cell Counting Kit-8 (CCK-8) and live/dead cell-staining test synergistically. In CCk-8 SIRC cells were seeded in 96well plates at the density of $5.0 \times 10^{4}$ cells $/ \mathrm{mL}$ and cultured for $24 \mathrm{~h}$. Next the cells were divided into 10 groups, each group containing six wells, and $2.5,5,7.5$ or $10 \mu \mathrm{g} / \mathrm{mL}$ Tet free in solution and $10,20,30,40$ or $50 \mu \mathrm{g} / \mathrm{mL}$ Tet encapsulated in liposomes were added to the wells that corresponded to each experimental group, while fresh culture medium was added to the wells in the control group. After $2448 \mathrm{~h}$ co-incubation, the cells were washed with PBS three times, and $100 \mu \mathrm{L}$ of $10 \%$ CCK-8 solution was added to each well and incubated for $30 \mathrm{~min}$, then the 96-well plates were analyzed spectrophotometrically at $450 \mathrm{~nm}$ with a microplate reader (SpectraMax M3; Molecular Devices), and after being compared with the control-group cells, the percentage of viable cells were determined; In the live/dead cell-staining test, SIRC cells $\left(5 \times 10^{5}\right)$ were seeded into a laser confocal cell-culture dish, and after $24 \mathrm{~h}$ incubation, cells were washed twice with PBS and fresh culture medium containing various PFOB@LIP-Tet formulations were added. After 24 h coincubation, cell culture was removed and cells were washed twice with PBS, next, dyes were added and coincubated for $15 \mathrm{~min}$. After being washed with PBS twice, all samples were observed under a confocal laser scanning microscope (CLSM, Nikon A1, Japan).

\section{Cellular Uptake of PFOB@LIP-Tet}

The cellular uptake of PFOB@LIP-Tet in SIRC cells was detected by CLSM and flow cytometry (FCM, FACS Vantage, Becton Dickinson, USA). SIRC cells $\left(5 \times 10^{3}\right)$ were seeded into laser confocal culture dishes and divided into two groups randomly, including normal cell group and inflamed cell group, and after $12 \mathrm{~h}$ incubation, culture mediums in the normal cell group were replaced by fresh culture mediums and culture mediums in inflamed cell group were replaced by culture mediums containing LPS $(500 \mathrm{ng} / \mathrm{mL})$.
After six hours incubation, culture medium of two groups were discarded and cells were washed twice with PBS, and next new cell culture mediums containing DiI $\left(\lambda_{\text {excitation }} /\right.$ $\left.\lambda_{\text {emission }}=549 \mathrm{~nm} / 565 \mathrm{~nm}\right)$ labeled PFOB $@$ LIP-Tet $(100 \mu \mathrm{g} /$ $\mathrm{mL}$ ) were added. After different intervals of co-incubation, the nucleus of all SIRC cells was stained with DAPI $\left(\lambda_{\text {excitation }} / \lambda_{\text {emission }}=364 \mathrm{~nm} / 454 \mathrm{~nm}\right)$, then the extent of cellular in two groups were observed and recorded with CLSM. Furthermore, the quantitative uptake of PFOB@LIP-Tet in SIRC cells of both groups at different intervals was retested and analyzed by FCM.

\section{Dispersion and Retention of PFOB@LIP-Tet on Ocular Anterior Segments}

Dispersion and retention of PFOB@LIP-Tet on ocular anterior segments in normal eye and dry eye were detected by FLI system (Cri Inc., Woburn, MA, USA). Typically, rabbits were divided into two groups, normal eye group and DED eye group, next pentobarbital sodium $(3 \%, 1 \mathrm{~mL} / \mathrm{kg})$ was used to sedate rabbits, then $30 \mu \mathrm{L}$ ATS containing DiR $\left(\lambda_{\text {excitation }} / \lambda_{\text {emission }}=748 \mathrm{~nm} / 780 \mathrm{~nm}\right)$ labeled PFOB $@$ LIPTet $(1 \mathrm{mg} / \mathrm{mL})$ was dropped onto the ocular surface, then the relative fluorescence intensity of nanoparticles, which flew out with tears, were observed and recorded with a in vivo imaging system (IVIS) Spectrum (LB983, Bold, Germany). Then we could compare the quantity of the nanoparticles in normal eyes and DED eyes immediately at different intervals. Various segments of eyes in two groups were extracted and detected at $2 \mathrm{~h}$. In addition, rabbits from the two groups also were treated with the ATS that contained the same concentration of DiI-labeled liposomes and placed in a dark environment. Two hours later, the corneas were dissected, put into a tissue well and soaked in tissue-Tek optimum cutting-temperature compound. Sequentially, tissue wells were frozen on dry ice and stored at $-70^{\circ} \mathrm{C}$. The frozen samples were cut into $10 \mu \mathrm{m}$ sections with a cryostat microtome (CM1860, LEICA, Germany). Next, the cornea cells were fixed by paraformaldehyde (4\%) and the sections were fixed in mounting medium and sealed. Samples were observed and photographed with a CLSM.

\section{Anti-inflammation Effects of Liposomes in vitro}

The anti-inflammation effects of PFOB@LIP-Tet formulations in vitro were synthetically assessed by the related inflammatory cytokines release and the survival rates of 
cells after treatment. SIRC cells $\left(5 \times 10^{4}\right)$ were seeded in six-well plates and cultured for $24 \mathrm{~h}$. To induce inflammation, culture mediums containing LPS $(500 \mathrm{ng} / \mathrm{mL})$ were added and co-incubated for six hours. After stimulation by LPS, culture mediums were removed, and cells were washed twice with PBS, then fresh culture medium (without LPS) containing free Tet, PFOB@LIP and PFOB@LIP-Tet were added. The cells that were stimulated by LPS but not treated by free Tet or liposomes were used as the control group. The concentration of Tet in the Tet group and PFOB@LIP-Tet group was the same (5 ug/ $\mathrm{mL})$. All cells in every group were halved. One half of cells were detached from the plates after being incubated for 24 and $48 \mathrm{~h}$, washed with PBS and resuspended into $500 \mu \mathrm{L}$ binding buffer, and incubated with FITC-conjugated annexin V (Sanjian, Hangzhou, China) and propidium iodide (PI, Sigma) at room temperature in dark for $15 \mathrm{~min}$, then the survival cells were detected by flow cytometry. The other half of cells were harvested from the plates after $24 \mathrm{~h}$ culture for RNA extraction and the culture medium was collected too. Total RNA was isolated through reacting with TRIzol reagent following the manufacturer's protocol. The extracted RNA was stored at $-80^{\circ} \mathrm{C}$ for reverse-transcription PCR. Next, RNA $(2 \mu \mathrm{g})$ of every group was used and the first-strand cDNA was synthesized subject to instructional protocols with the high-capacity cDNA reverse-transcription kit (Servicebio, Wuhan, China), then real-time PCR was performed using a LightCycler 96 real-time PCR system (Bio-rad, CA, USA). Specific primers ( $\mathrm{PEG}_{2}$ [NM_001171406.1], VEGF [XM_017345155.1], IL-1 $\beta$ [NM_001082201.1], TFN- $\alpha$ [NM_001082263.1]) were used. In addition, the collected culture mediums were centrifuged at $1000 \mathrm{~g}$ to remove the cell formulations, then ELISA was performed as soon as possible.

\section{Therapeutic Efficacy Evaluation}

Animals from all groups were respectively treated with 30 $\mu \mathrm{L}$ ATS, PFOB@LIP-ATS suspension, Tet-ATS and PFOB@LIP-Tet-ATS suspension topically, three times a day. The concentration of Tet provided to every rabbit in Tet-ATS group and PFOB@LIP-Tet was same $(0.1 \mathrm{mg} / \mathrm{mL})$. At different intervals, rabbits were sedated by pentobarbital sodium $(3 \%, 0.8 \mathrm{~mL} / \mathrm{kg})$, then $2 \mu \mathrm{L} 1 \%$ fluorescein sodium or rose bengal was dropped into the conjunctival sac. The fluorescence intensity on the cornea was quantified under slit-lamp (LS-6, Sunkingdom Medical Instrument, Chongqing, China). Furthermore, for analyzing the staining results, a standardized score scale $(0=$ absent, $1=$ minimal, $2=$ mild, $3=$ =moderate, $4=$ marked and $5=$ severe) was applied. ${ }^{34}$ After seven days' treatment, Schirmer test was performed to measure the tear secretion: insert a Schirmer tear test trip (TQM Schirmer, Indian) into the external third of the lower eyelid for five minutes without topical anesthesia and record the length of strips wetted by tears. After seven days' therapy, trapezoidal desk of acetate fiber filter membrane was placed on the nasal and temporal bulbar conjunctiva to collect conjunctival impression cytology specimens. Samples were stained with hematoxylin and periodic acid-Schiff (PAS) for identification of goblet cells. The number of goblet cells was counted under a light microscope (DMi1, LEICA, Solms, Germany). Then all rabbits were sacrificed, and corneal tissues of model eyes were exacted. Each cornea was halved. One half was stored at $-80^{\circ} \mathrm{C}$ for further RNA isolation and PCR performance to certify the translations of gene VEGF, IL- $1 \beta, \mathrm{TNF}-\alpha$ and $\mathrm{PEG}_{2}$ in line with the procedure introduced above. The other half was fixed in paraformaldehyde (4\%), dehydrated in a graded ethanol series, and embedded in paraffin. Thin sections (5 $\mu \mathrm{m})$ were obtained and stained with H\&E, and then were observed and recorded under a light microscope (DMil, LEICA, Solms, Germany). In addition to analysis of corneal epithelial thickness, apoptotic cells were analyzed by TUNEL assay. Following fixation and permeabilization, samples were incubated with mixtures of TdT solution and fluorescein isothiocyanate dUTP solution from a TUNEL assay kit (Servicebio, Wuhan, China). After two hours incubation at $37^{\circ} \mathrm{C}$ in a humidity chamber, samples were counterstained with DAPI for identification of cell nuclei. Under a fluorescence microscope (ECLIPSE C1, Nikon, Japan), the number of TUNEL-positive apoptotic cells were counted at three randomly selected fields.

\section{Eye Pressure Measurement}

To further clarify the impact of PFOB@LIP-Tet formulations on eye pressure, administration time was prolonged to 14 day. At the time of 0,7 and 14 days, one drop of ropivacaine hydrochloride $(0.4 \%)$ was given to the model eyes to alleviate the discomfort resulting from operation, then a contact tonometer (Tono-Pen AVIA, Reichert, CA, USA) was used to detect the eye pressure of each model eye.

\section{Statistical Analysis}

Data were presented as the means $\pm \mathrm{SD}$. Statistical analysis was performed with GraphPad Prism version 8.3.0 (GraphPad Software, CA, USA) through multiple T-test, 
row mean with SD, Simple linear regression, ordinary oneway ANOVA and two-way ANOVA. Statistical significance was set to $P<0.05$.

\section{Results}

\section{Observations of Physicochemical Properties of Liposomes}

As showen in Figure 2A, we prepared the PFOB@LIP and PFOB@LIP-Tet, which were resuspended in PBS at same concentration and the transparency of Tet solution, PFOB@LIP and PFOB@LIP-Tet suspension was different. Diameters of PFOB@LIP and PFOB@LIP-Tet, respectively were measured. The average size of PFOB@LIP was 79.4 \pm 7.7 nm and that of PFOB@LIPTet was 103.4 $\pm 7.8 \mathrm{~nm}$ (Figure 2B). Their PDI both in PBS and ATS was <0.25. Under TEM, PFOB@LIP and PFOB@LIP-Tet had a relatively regular spherical coreshell structure: the lipid bilayer with or without Tet inserted served as the shell while the liquid phase-changeable PFOB was the core. The transparency of PFOB@LIPTet was decreased compared with PFOB@LIP (Figure 2C) and with PFOB wrapped in liposomes, the liquid could easily be phase-changed in a vacuum when a high-speed electron beam was used during TEM, so the diameter of liposomes may be discordant with that measured by particle size analyzer. Meanwhile, the size change of PFOB@LIP-Tet in PBS was detected for seven days in succession (Figure 2D). Besides, the zeta potential of PFOB@LIP and PFOB@LIP-Tet was respectively -6.0 $\pm 1.2 \mathrm{mV}$ and $-21.8 \pm 0.6 \mathrm{mV}$ (Figure 2E), and UV-visNIR spectrum showed that PFOB@LIP-Tet and Tet were featured with a characteristic absorption peak at $282 \mathrm{~nm}$, while PFOB@LIP exhibited no such characteristic absorption peak (Figure 2F). All these differences between PFOB@LIP and PFOB@LIP-Tet implied successful loading of Tet on liposomes. Then it was calculated that Tet encapsulation efficiency and loading capacity were about
A

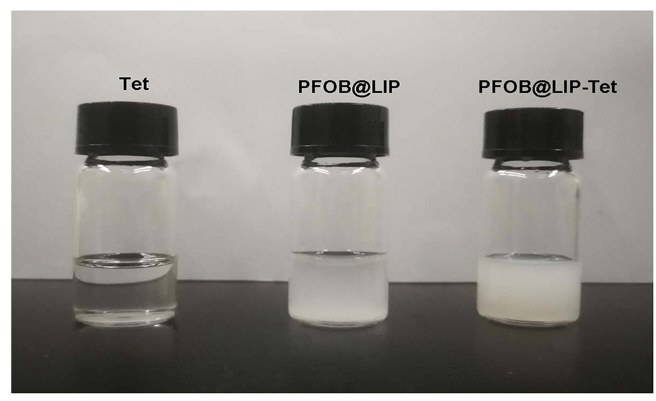

C

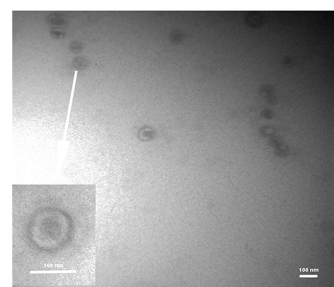

PFOB@LIP

E

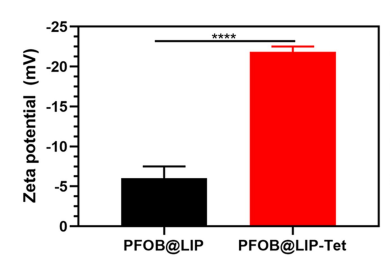

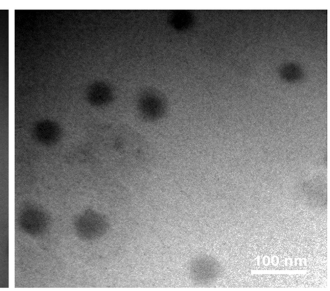

PFOB@LIP-Tet

$\mathbf{F}$

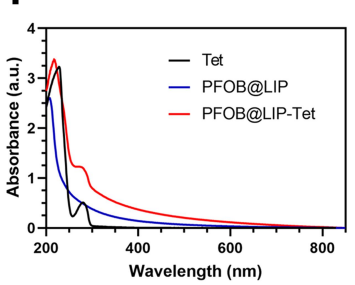

B
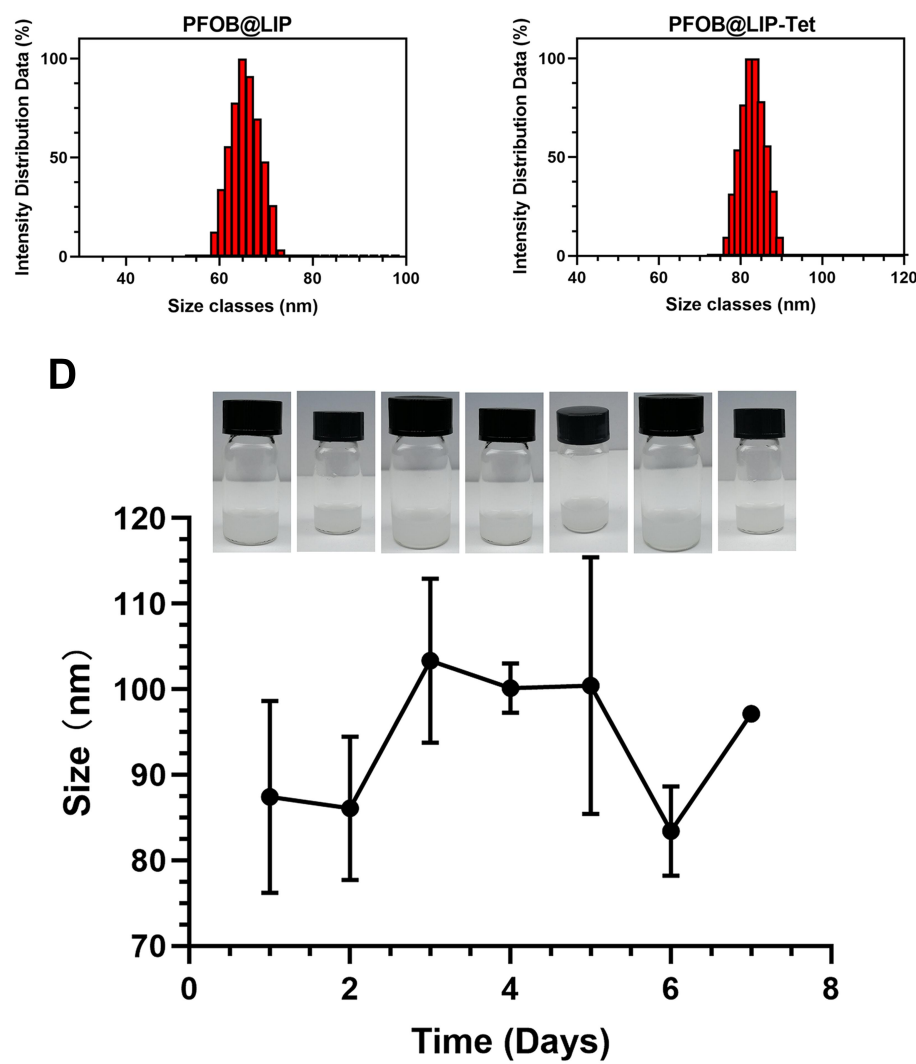

Figure 2 (A) Digital photographs of properties of PFOB@LIP-Tet formulations (I mg/mL). (B) Size of PFOB@LIP and PFOB@LIP-Tet (I00 $\mu g / \mathrm{mL})$. (C) TEM of PFOB@LIP and PFOB@LIP-Tet $(250 \mu \mathrm{g} / \mathrm{mL})$. (D) PFOB@LIP-Tet size distribution with prolonged time duration. Insert: digital photos of the PFOB@LIP-Tet suspended in PBS (2.5 mg/

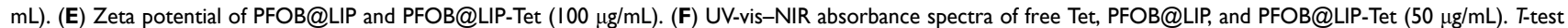
and Row mean with SD were performed for analysis (P 0.000I). 
$79.9 \%$ and $49.4 \%$, respectively, according to the standard curve of Tet absorption spectra (Figure $3 \mathrm{~A}$ and $\mathrm{B}$ ). The cumulative Tet release was calculated according to the calibration curve of Tet performed by HLPC (Figure 3C), and results showed a slow release of up to $2.2 \pm 0.1 \%, 4.2$ $\pm 0.1 \%$ and $76.2 \pm 0.2 \%$ at $480 \mathrm{~min}$ respectively at $4^{\circ} \mathrm{C}, 25^{\circ}$ $\mathrm{C}$ and $33^{\circ} \mathrm{C}$ (Figure 3D), meaning that Tet was easily released from PFOB@LIP-Tet at corneal temperature and terribly hard for that performance at storage temperature and room temperature.

\section{Cell Viability of SIRC Cells Treated with PFOB@LIP-Tet Formulations}

Evaluation of possible cytotoxicity of free Tet and PFOB@LIP-Tet was done by assessing the viability of SRIC cells using CCK-8. As the results showed, the cell viability was dose-dependently decreased as the concentrations of Tet increased, no matter free in solution or encapsulated in PFOB@LIP-Tet. For concentration of Tet free in solution from 2.5 to $10 \mu \mathrm{g} / \mathrm{mL}$ cell viability, respectively was $93.1 \pm 5.3 \%, 84.8 \pm 0.9 \%, 74.9 \pm 0.7 \%$ and $57.7 \pm 0.6 \%$ after $24 \mathrm{~h}$ incubation, and that was $88.2 \pm 4.6 \%$, $82.1 \pm 3.0 \%, 69.3 \pm 4.8 \%$ and $54.6 \pm 2.9 \%$ after incubation for $48 \mathrm{~h}$. For concentration of Tet encapsulated in PFOB@LIP-Tet from 10 to $50 \mu \mathrm{g} / \mathrm{mL}$, cell viability was respectively $91.6 \pm 6.7 \%, 73.4 \pm 2.7 \%, 68.8 \pm 1.1 \%, 64.3$ $\pm 1.7 \%$ and $51.9 \pm 4.2 \%$ after 24 hco-culture, and that is $77.3 \pm 2.8 \%, 67.3 \pm 6.0 \%, 52.4 \pm 4.9 \%, 41.1 \pm 2.0 \%$ and 35.5 $\pm 1.7 \%$ after for $48 \mathrm{~h}$ co-culture. Comparing the cell viability of Tet free in solution and encapsulated in PFOB@LIP-Tet at the concentration of $10 \mu \mathrm{g} / \mathrm{mL}$ (Figure 4A), statistical significance was evident. The concentration of Tet was fixed at $5 \mu \mathrm{g} / \mathrm{mL}$, and in live/dead staining images, the prevalence of green fluorescent cells
A

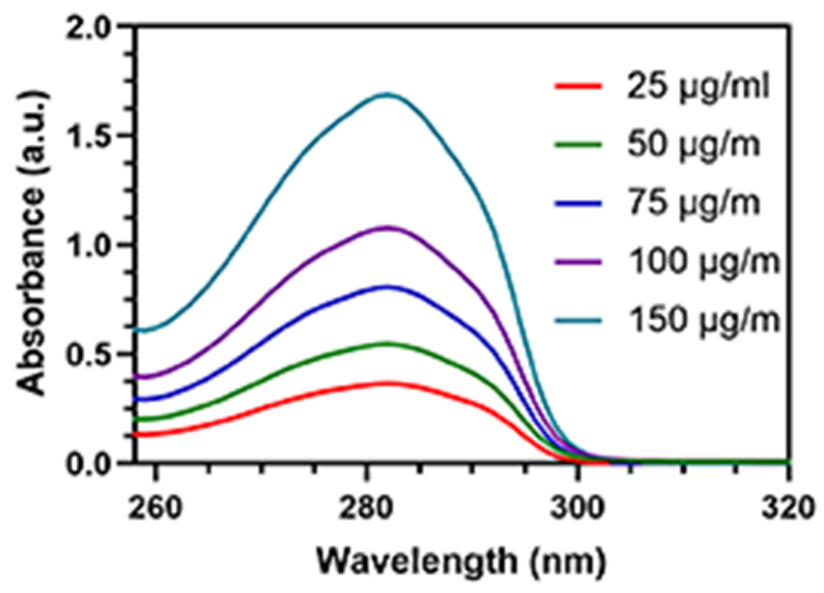

C

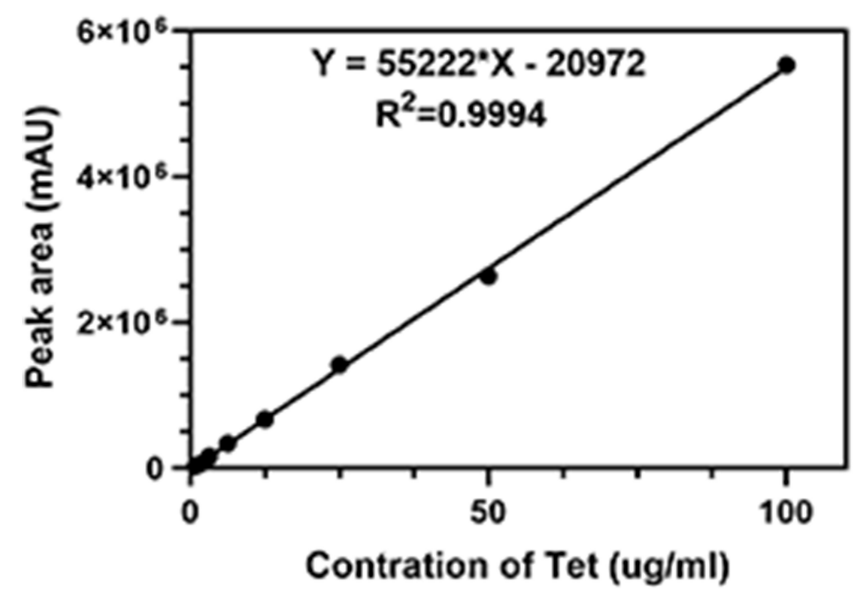

B

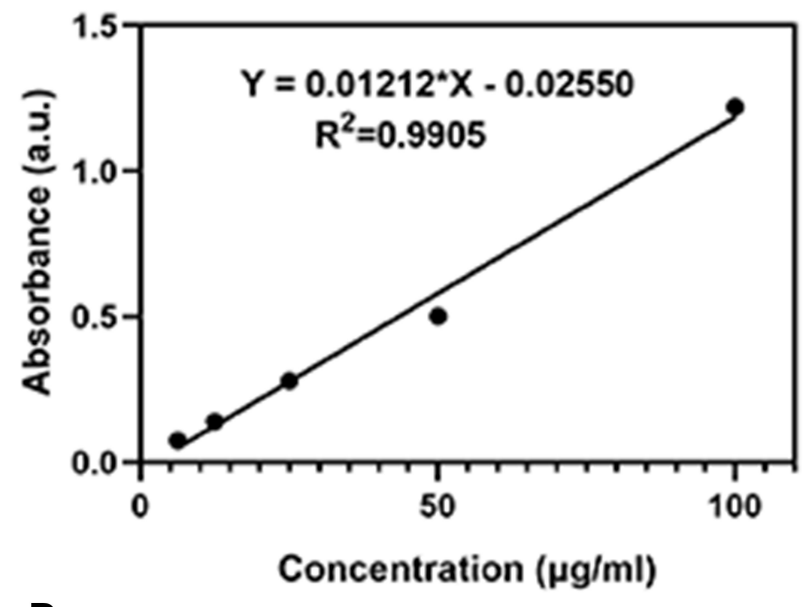

D

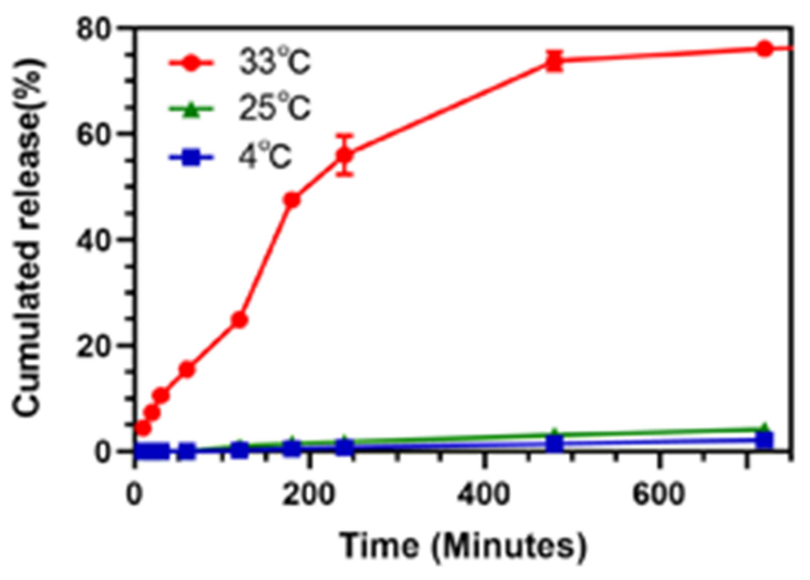

Figure 3 (A) UV-vis-NIR absorbance spectra of Tet at elevated concentrations. (B) A calibration curve of Tet for the quantitation of its loading efficiency. (C) A calibration curve of Tet with concentration from 0.8125 to $100 \mu \mathrm{g} / \mathrm{mL}$ for the quantitation of its cumulative releases. (D) In vitro cumulative release of Tet from PFOB@LIP-Tet in ATS solution at $4^{\circ} \mathrm{C}, 25^{\circ} \mathrm{C}$ and $33^{\circ} \mathrm{C}$. Linear regression was performed. 
(live cells) was the evidence that this concentration of Tet was safe for SIRC cells, no matter encapsulated in liposomes or free in solutions (Figure 4B).

\section{PFOB@LIP-Tet Accumulation in SIRC Cells}

The cellular uptake of PFOB@LIP-Tet between normal cells and inflamed cells was compared with CLSM and FCM. As shown in CLSM images, almost all inflamed SIRC cells were DiI-positive while a small number of normal SIRC cells were DiI-positive after incubation with DiI-labeled PFOB@LIP-Tet for 30 min (Figure 5A). After being analyzed by FCM, it was calculated that about 91.1\% of inflamed SIRC cells were DiI-positive, while for normal SIRC cells, that number was just 7.6\% (Figure 5B and C). All these results suggested that the uptake ability of SIRC cells was significantly increased after stimulation by LPS, in other words, it is much easier for inflamed SIRC cells to take in PFOB@LIP-Tet compared to normal SIRC cells.

\section{PFOB@LIP-Tet Accumulation and Penetration in Rabbit Eyes}

PFOB@LIP-Tet accumulated in normal eyes and dry eyes was compared indirectly. The DiR-labeled PFOB@LIPTet suspended in ATS were dropped onto the ocular surface to explore the distribution of liposomes in the anterior parts of eyes, and as the relative fluorescent images showed (Figure 6A), the liposomes flowed out of canthus and eyelids as soon they were dropped into normal eyes, but those dropped into dry eyes remained, and began to be cleared out at $20 \mathrm{~min}$, and for the DiR fluorescent intensity of liposomes out of normal eyes highest at this time, we guessed that DiR-labeled liposomes may have been washed out entirely. At $30 \mathrm{~min}$, fluorescent intensity outside the dry eye ascended to a peak (Figure S1A), we supposed that the liposomes that had not resided in or adhered to ocular surface may have been cleared totally. Then aqueous humor, cornea, conjunctiva, crystalline lens, vitreous body and iris were exacted and observed by FLI system (Figure 6B), and after analysis (Figure S1B), the results corresponded to our hypothesis: only the conjunctiva of normal eyes had feeble fluorescent intensity but both cornea and conjunctiva of dry eyes showed fluorescent signals, especially the iris, which showed strong fluorescent intensity. Then DiI-stained PFOB@LIP-Tet were used to verify the accumulation of liposomes in corneal epithelium. CLSM results showed strong Dil fluorescent intensity in corneal epithelium of dry eye, but almost none in the normal corneal epithelium (Figure 6C)

\section{Assessments of Anti-inflammation Effects in vitro}

The anti-inflammation activations of PFOB@LIP-Tet formulations were detected by analyzing the expression of related inflammatory cytokines including VEGF, IL-1 $\beta$, TNF- $\alpha$ and $\mathrm{PEG}_{2}$ directly. From PCR results, we could find that the translations of gene VEGF, IL- $1 \beta$, TNF- $\alpha$ and $\mathrm{PEG}_{2}$ of the inflamed cells were significantly downregulated compared with those in the control group after being treated by PFOB@LIP-Tet formulations (Figure 7A). Furthermore, the corresponding cytokines released into culture medium were detected by ELISA, and the results showed the concentrations of cytokines were decreased by PFOB@LIP-Tet formulations (Figure 7B). Besides, transplantation and expression level of all four cytokines in the PFOB@LIP-Tet group was shown to be significantly the lowest by analyzing the PCR and ELISA results (Figure $7 \mathrm{~A}$ and $\mathrm{B})$. Then we examined the survival rates of the cells treated by PFOB@LIP-Tet after stimulation by LPS. The survival rate of inflamed cells treated by PBS, PFOB@LIP, Tet and PFOB@LIP-Tet for 24 h was 59.97 $\pm 0.566 \%, \quad 66.67 \pm 0.628 \%, \quad 74.7 \pm 0.9 \%$, and $80.9 \pm 0.9 \%$ (Figure S2A), and for $48 \mathrm{~h}$, that was $22.4 \pm 0.4 \%, 27.5$ $\pm 0.5 \%, 40.9 \pm 0.3 \%$ and $65.5 \pm 0.6 \%$, respectively (Figure S2B). The survival rate of normal cells was respectively $81.5 \pm 0.8 \%$ and $77.6 \pm 0.6 \%$ after being incubated with PBS for $24 \mathrm{~h}$ and $48 \mathrm{~h}$. The survival rate of inflamed SIRC cells was increased after treatment by PFOB@LIP-Tet formulations, and among them, the survival rate of SIRC cells in the PFOB@LIP-Tet group was highest (Figure S2A and $\underline{\mathrm{S} 2 \mathrm{~B}})$. By decreasing the cytokines concentration and increasing the survival rates of inflamed cells effectively, the anti-inflammation function of PFOB@LIP-Tet was achieved effectively.

\section{Assessment of Therapeutic Effects and Side Effects on DED in vivo}

The therapeutic effects of PFOB@LIP-Tet-ATS were evaluated by the recovery of corneal epithelium and the tear secretions. As the corneal staining images showed, corneas with DED in the ATS, PFOB@LIP-ATS, Tet-ATS and PFOB@LIP-Tet-ATS groups showed different recovery progress: the DED cornea treated by PFOB@LIP-Tet- 
A
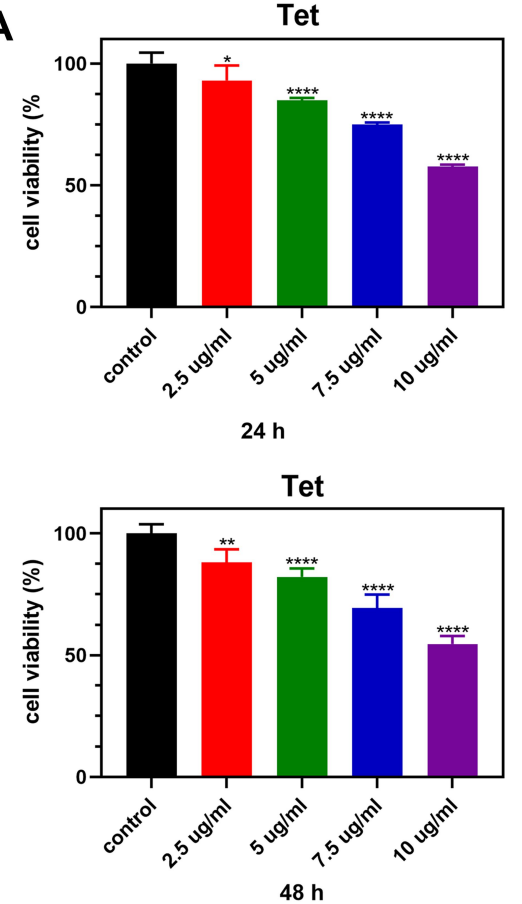

B

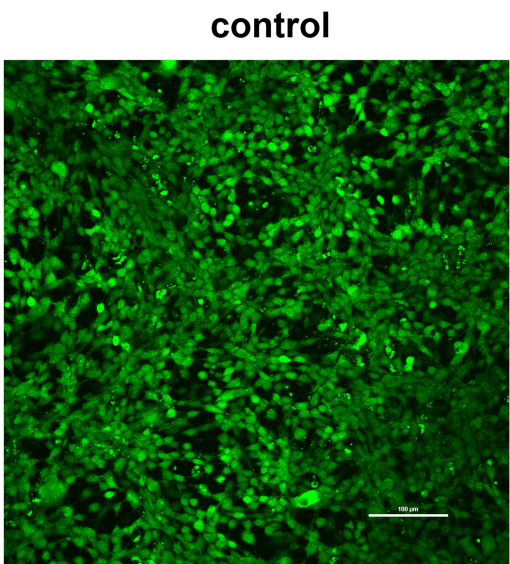

Tet

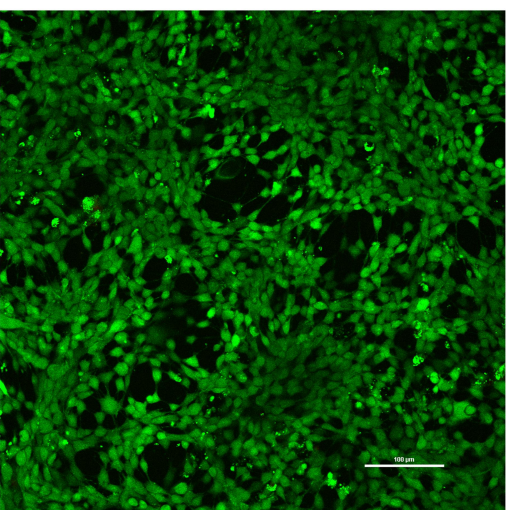

PFOB@LIP-Tet

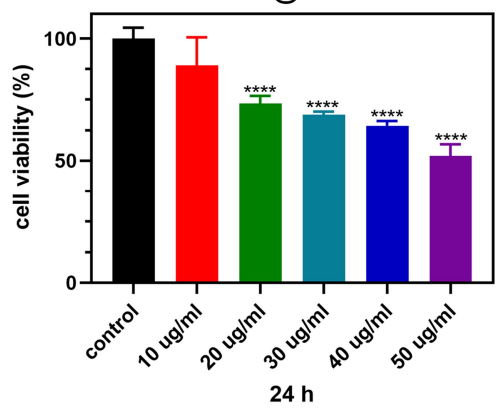

PFOB@LIP-Tet

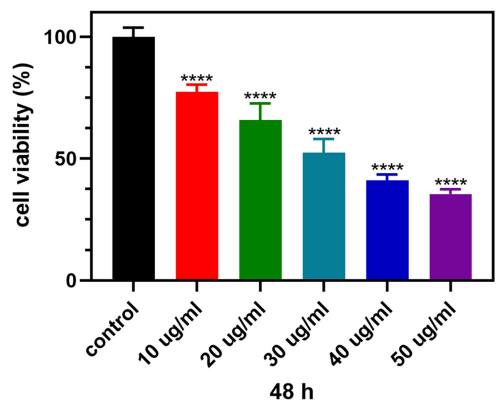

PFOB@LIP

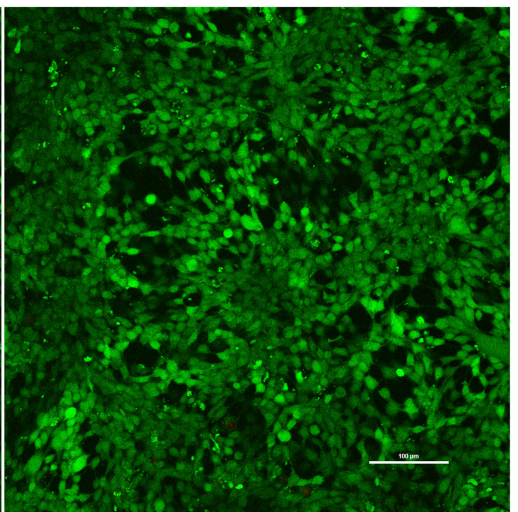

PFOB@LIP-Tet

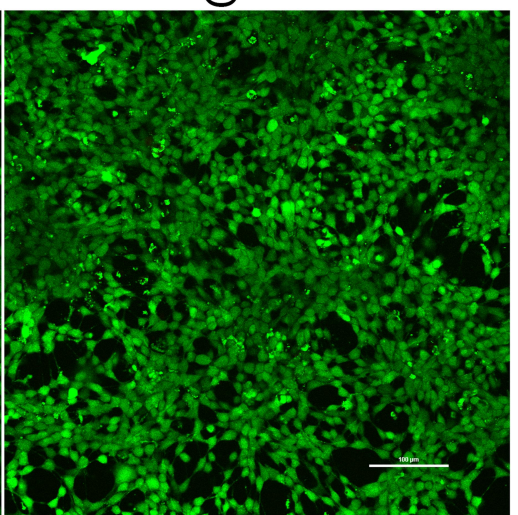

Figure 4 (A) Cell viability of SIRC cells after treated with Tet free in solution or encapsulated in PFOB@LIP-Tet at various concentrations after 24 h and 48 h incubation. (B) Live/dead staining images of SIRC cells treated for $24 \mathrm{~h}$ with variant PFOB@LIP-Tet (Tet: $5 \mu \mathrm{g} / \mathrm{mL})$. Ordinary one-way ANOVA was performed $(* P<0.05$, $* * P<0.0 \mathrm{I}$, $* * * P<0.0001)$. 
A

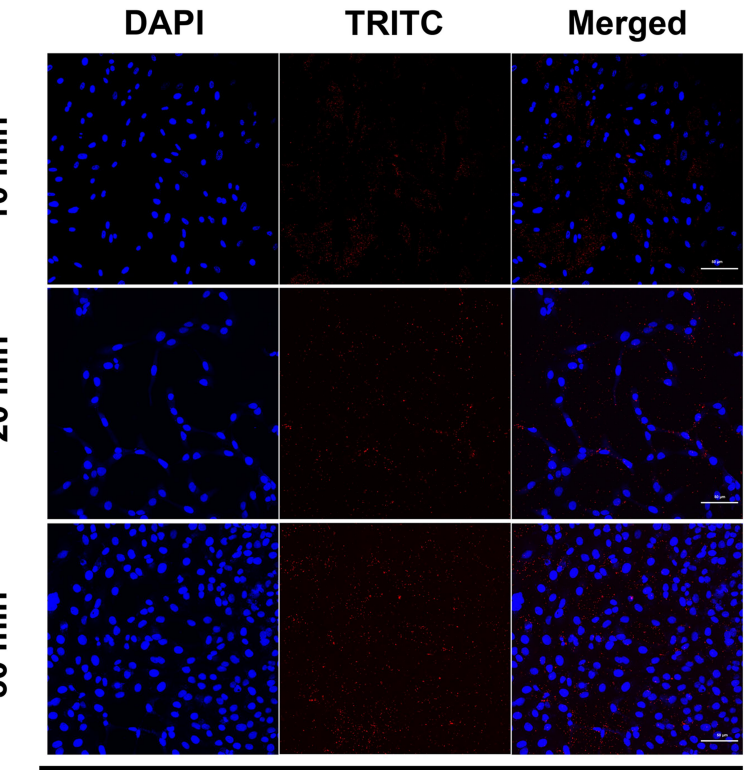

Normal SIRC cells

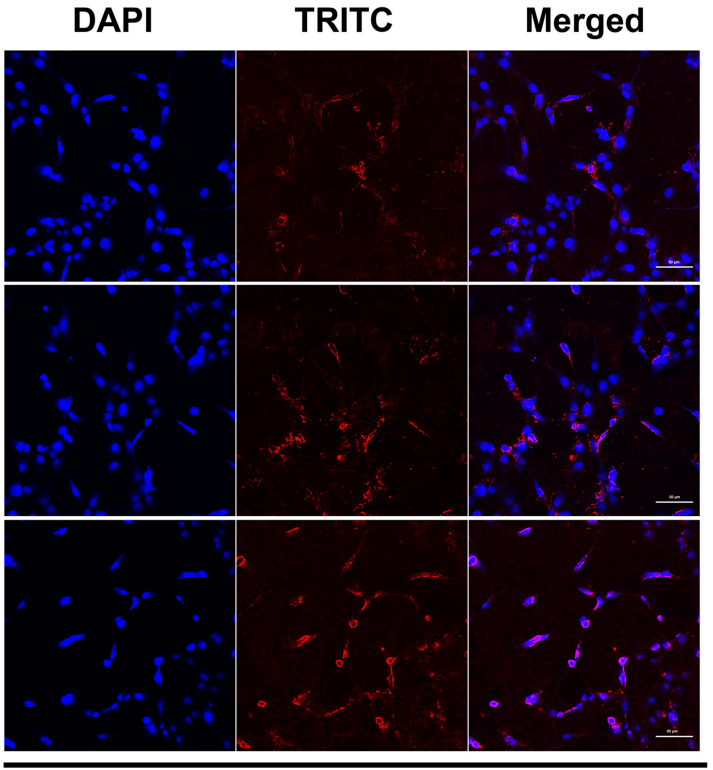

Inflammed SIRC cells
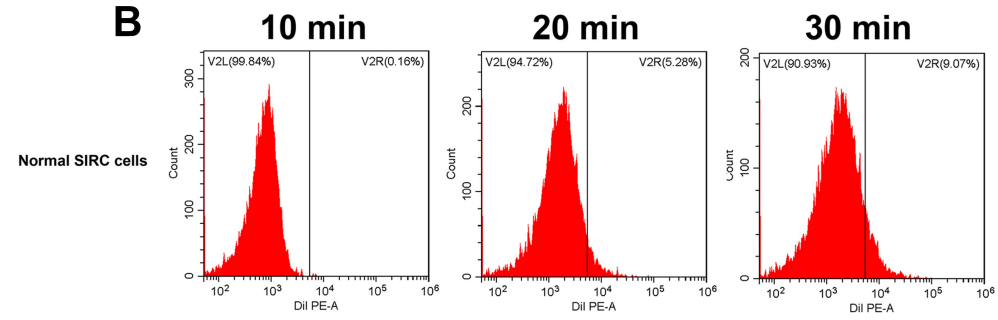

C
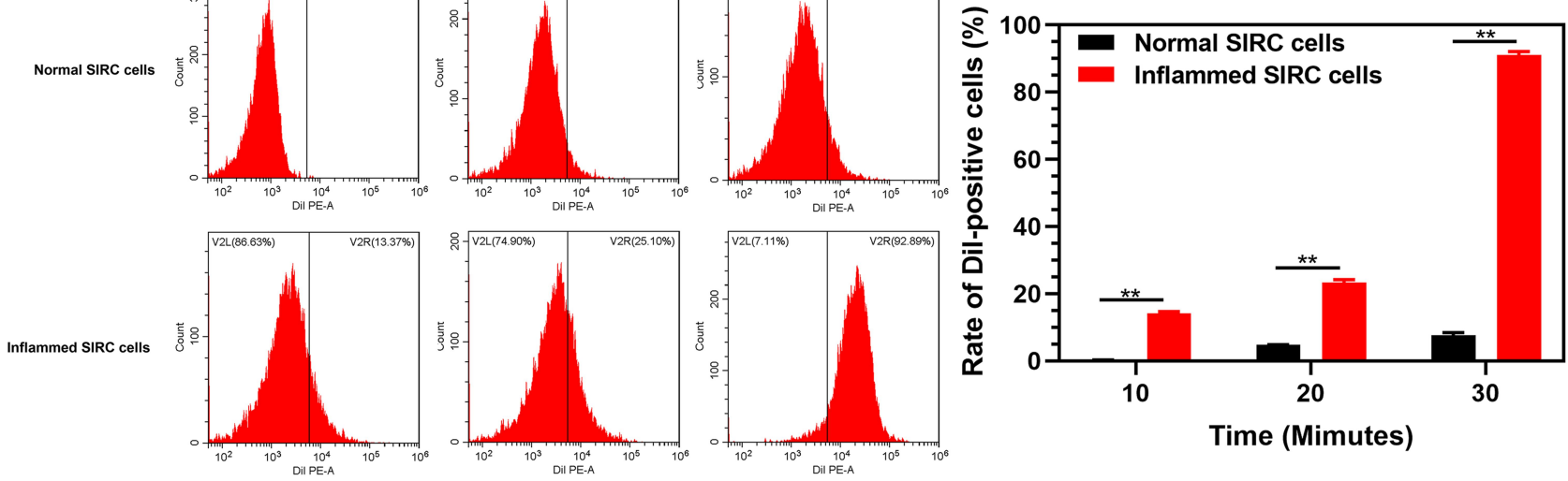

Figure 5 (A) Intracellular uptake of Dil-labeled PFOB@LIP-Tet by SIRC cells with or without being stimulated by LPS observed by CLSM at different intervals (PFOB@LIPTet: $100 \mu \mathrm{g} / \mathrm{mL}$ ). (B) Flow cytometry detection of intracellular uptake of Dil-labeled PFOB@LIP-Tet (I00 $\mu \mathrm{g} / \mathrm{mL})$. (C) Quantitative analysis of flow-cytometry. Multiple $t$-tests were performed $(* P<0.01)$.

ATS showed less staining area and slighter dyeing intensity than those in the ATS, PFOB@LIP-ATS, and Tet-ATS groups at any detection timing, no matter fluorescein sodium staining or rose Bengal staining (Figure 8A and B). Corneal staining of DED rabbits respectively treated by ATS, PFOB@LIP-ATS, Tet-ATS and PFOB@LIP-TetATS for seven days was scored at $3.7 \pm 0.5,3.2 \pm 0.4,1.5$ \pm 0.5 , and $0.5 \pm 0.5$ according to the standard score scale, and the analysis results of staining scores in succession showed meaningful difference (Figure 8C). Then Schirmer tests were performed to detect the tear secretion. The tear secretions volumes of DED eyes in the ATS, PFOB@LIPATS, Tet-ATS, and PFOB@LIP-Tet-ATS groups were 7.3 $\pm 1.1 \mathrm{~mm}, 8.5 \pm 0.9 \mathrm{~mm}, 11.5 \pm 1.5 \mathrm{~mm}$, and $11.8 \pm 1.3 \mathrm{~mm}$, respectively after seven days administration, and that of the normal group was $15.8 \pm 1.1 \mathrm{~mm}$. Next, H\&E and TUNEL staining were performed on the corneas dissected from all rabbit groups on the eighth day to detect the corneas in pathology, including corneal epithelium thickness and apoptosis of epithelial cells. After staining with H\&E, measured thickness of corneal epithelium respectively from the normal, ATS, PFOB@LIP-ATS, Tet-ATS, and PFOB@LIP-Tet-ATS groups was 68.3 $\pm 2.7 \mu \mathrm{m}, 19.1$ $\pm 1.1 \mu \mathrm{m}, 26.2 \pm 1.6 \mu \mathrm{m}, 36.8 \pm 0.7 \mu \mathrm{m}$, and $54.2 \pm 1.9 \mu \mathrm{m}$ (Figure 9A). TUNEL staining results told us that number of the apoptosis cells in the same corneal acreage from the 

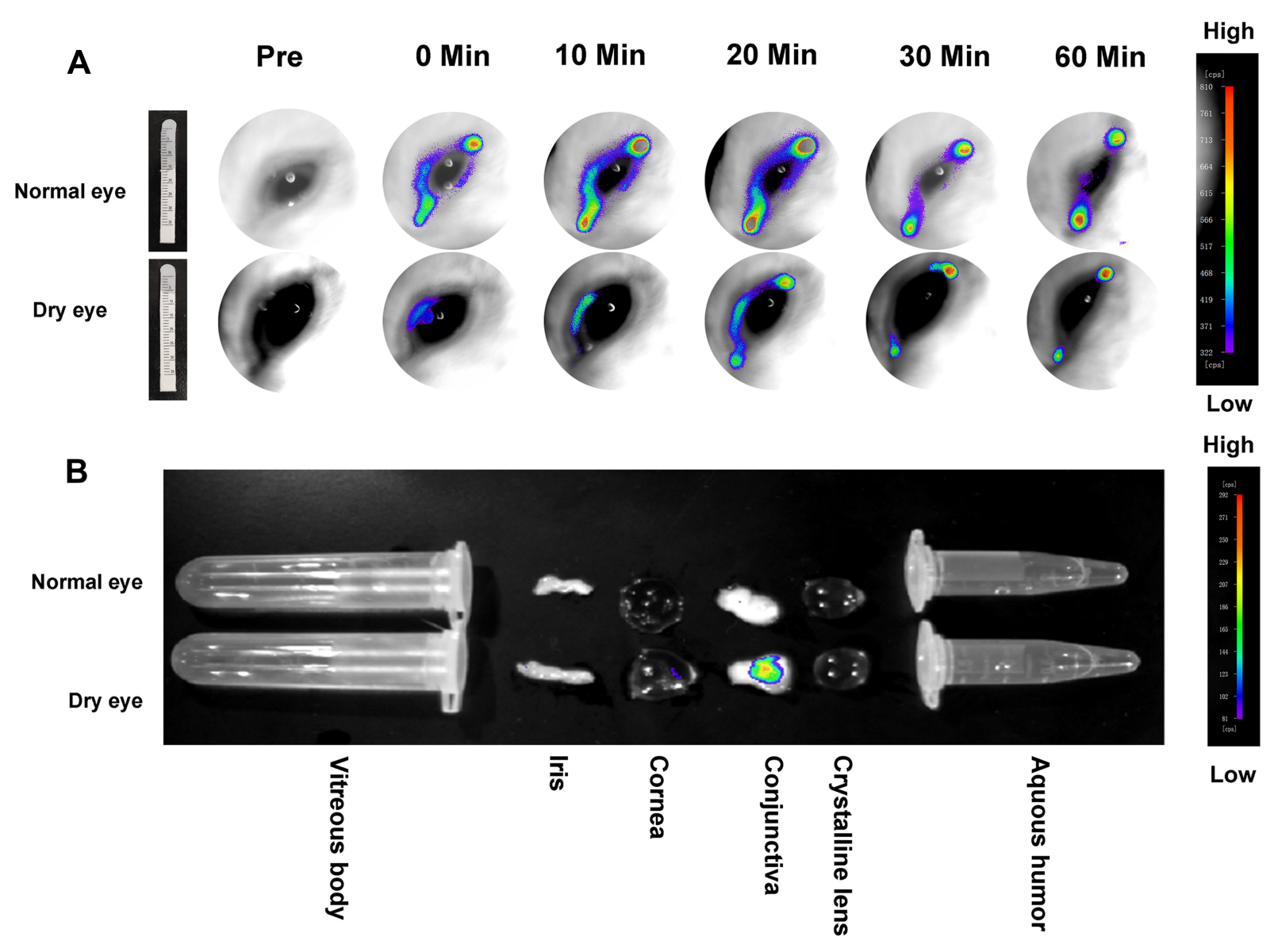

C

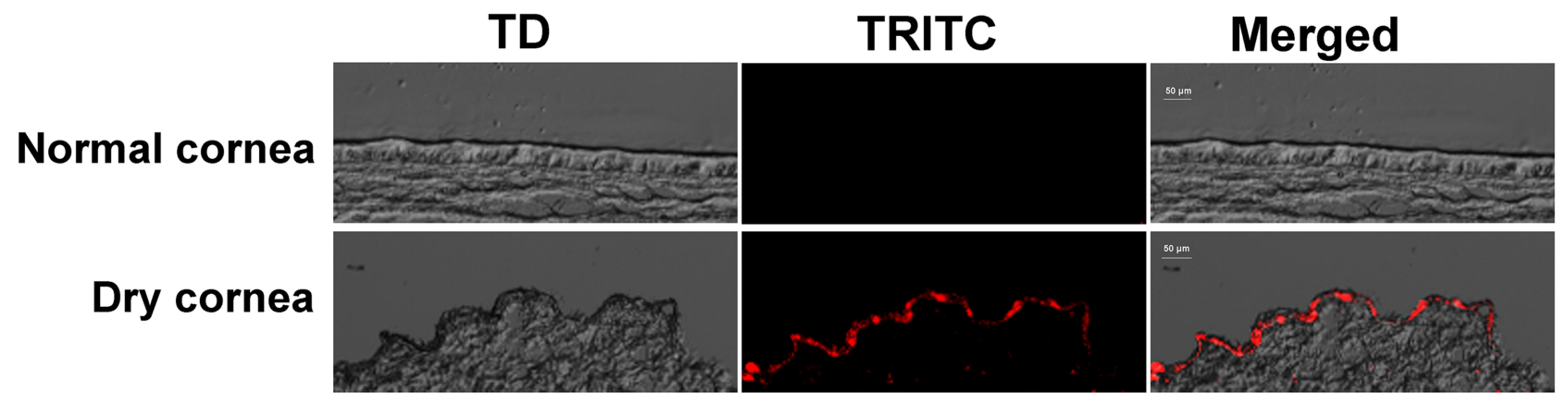

Figure 6 (A) Fluorescence images of DiR-labeled liposomes (PFOB@LIP-Tet: I mg/mL) flowed out of eyes at different time intervals. Insert: Schirmer test results of normal rabbit and DED rabbit. (B) Ex vivo fluorescence images of major eye segments dissected from rabbits two hours after DiR-labeled liposomes (PFOB@LIP-Tet: I mg/mL) was dropped. (C) Fluorescence images of Dil-labeled liposomes (PFOB@LIP-Tet: I mg/mL) in corneal epithelium two hours after liposomes were provided.

normal, ATS, PFOB@LIP-ATS, Tet-ATS, and PFOB@LIP-Tet-ATS groups was $2.7 \pm 0.9,360.0 \pm 23.6$, $236.3 \pm 39.0, \quad 113.7 \pm 14.4$, and $14.0 \pm 4.3$, respectively (Figure 9B). Stained by PAS, counted number of PASpositive cells in impression cytology collected from of DED rabbits of the normal, ATS, PFOB@LIP-ATS, TetATS, and PFOB@LIP-Tet-ATS groups was 2369.7 \pm 359.8 , $261 \pm 14.9, \quad 936.7 \pm 79.8, \quad 1772.3 \pm 34.5$ and $2414 \pm 179.8$ (Figure 9C). Translations of gene VEGF, IL-1 $\beta$, TNF- $\alpha$, and $\mathrm{PEG}_{2}$ in DED rabbit corneas were analyzed by PCR, and as the results showed, all these genes were downregulated after treatment by PFOB@LIP-Tet formulations (Figure 10). By analyzing the data of corneal staining scores, corneal epithelium thickness, tear secretion test, apoptotic cells number and goblet cell number, statistical significances were evident among the experimental groups. At last, we detected the eye pressure changes before and after treatment. The measured eye pressure in 
A

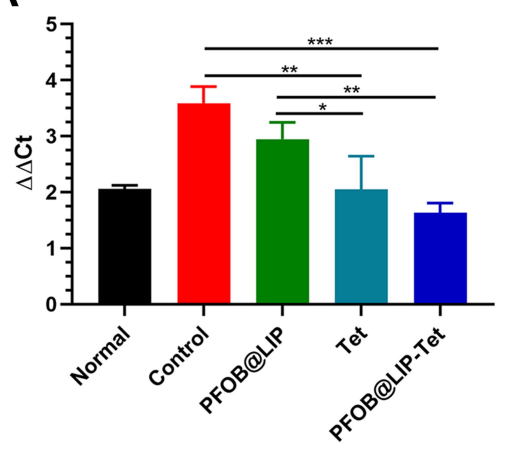

IL-1

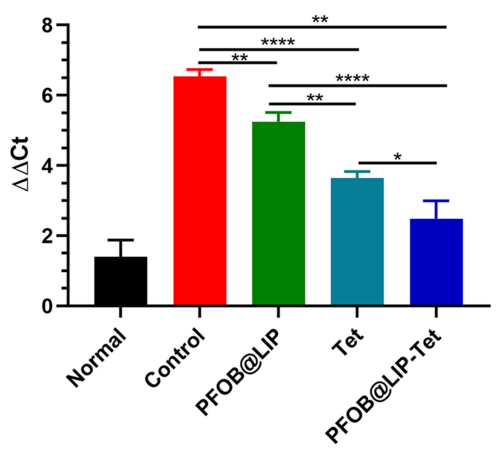

B

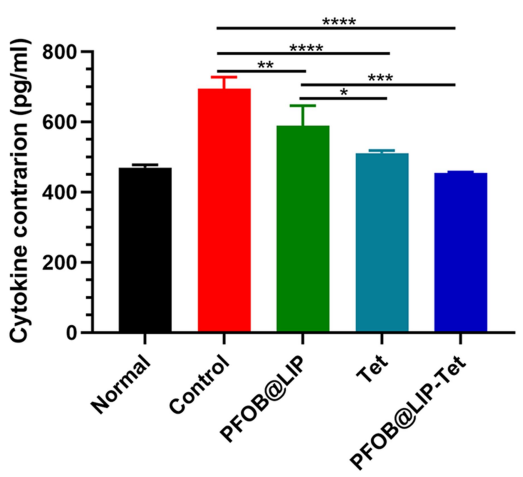

IL-1 $\beta$

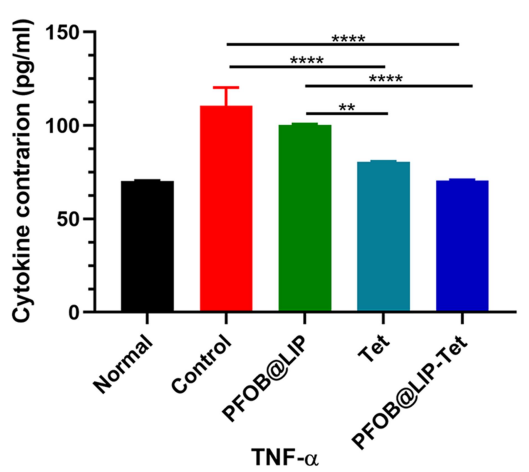

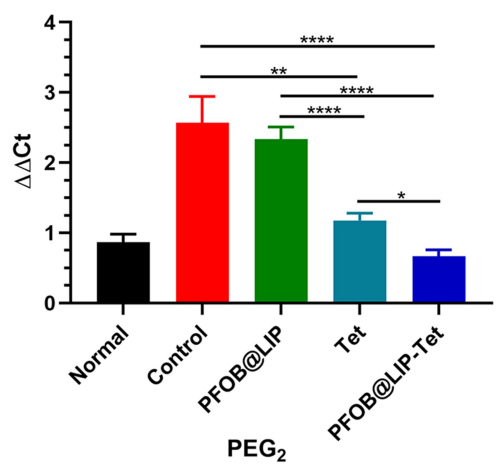
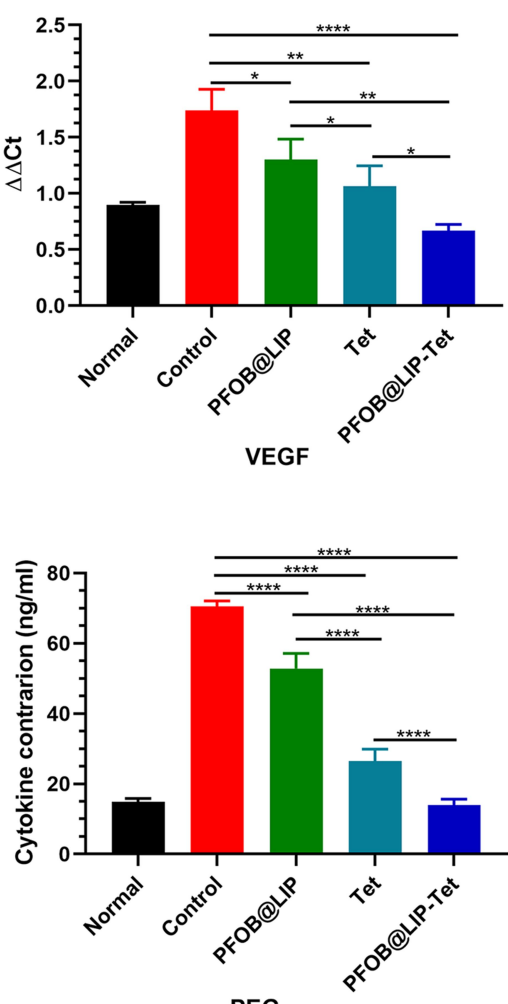

$\mathrm{PEG}_{2}$

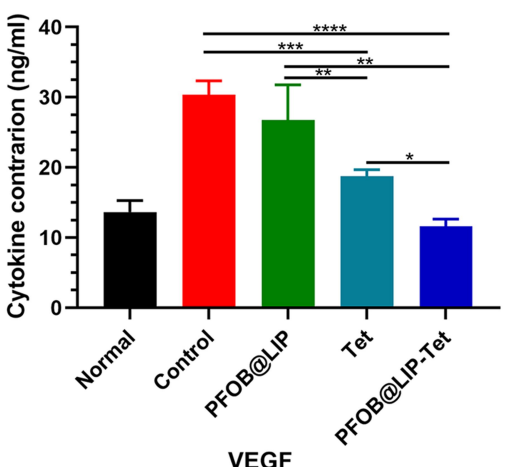

VEGF

Figure 7 (A) Gene translations of IL-I $\beta$, PEG 2 , VEGF, and TNF- $\alpha$ in normal SIRC cells and inflamed SIRC cells after incubated with PBS PFOB@LIP, Tet and PFOB@LIP-Tet (Tet: $5 \mu \mathrm{g} / \mathrm{mL}$ ) for 24 h. (B) Expression of IL-I $\beta$, PEG $_{2}$, VEGF, and TNF- $\alpha$ in normal SIRC cells and inflamed SIRC cells after incubation with PBS PFOB@LIP, Tet and PFOB@LIP-Tet (Tet: $5 \mu \mathrm{g} / \mathrm{mL}$ ) for $24 \mathrm{~h}$. The SIRC cells that were stimulated by LPS but not treated by free Tet or liposomes were used as the control group and the SIRC cells that were neither treated with LPS or liposomes were surveyed as normal group. Ordinary one-way ANOVA was performed $(* P<0.05, \quad * * P<0.01, * * * P<0.001$, $* * * * P<0.0001$ ) 


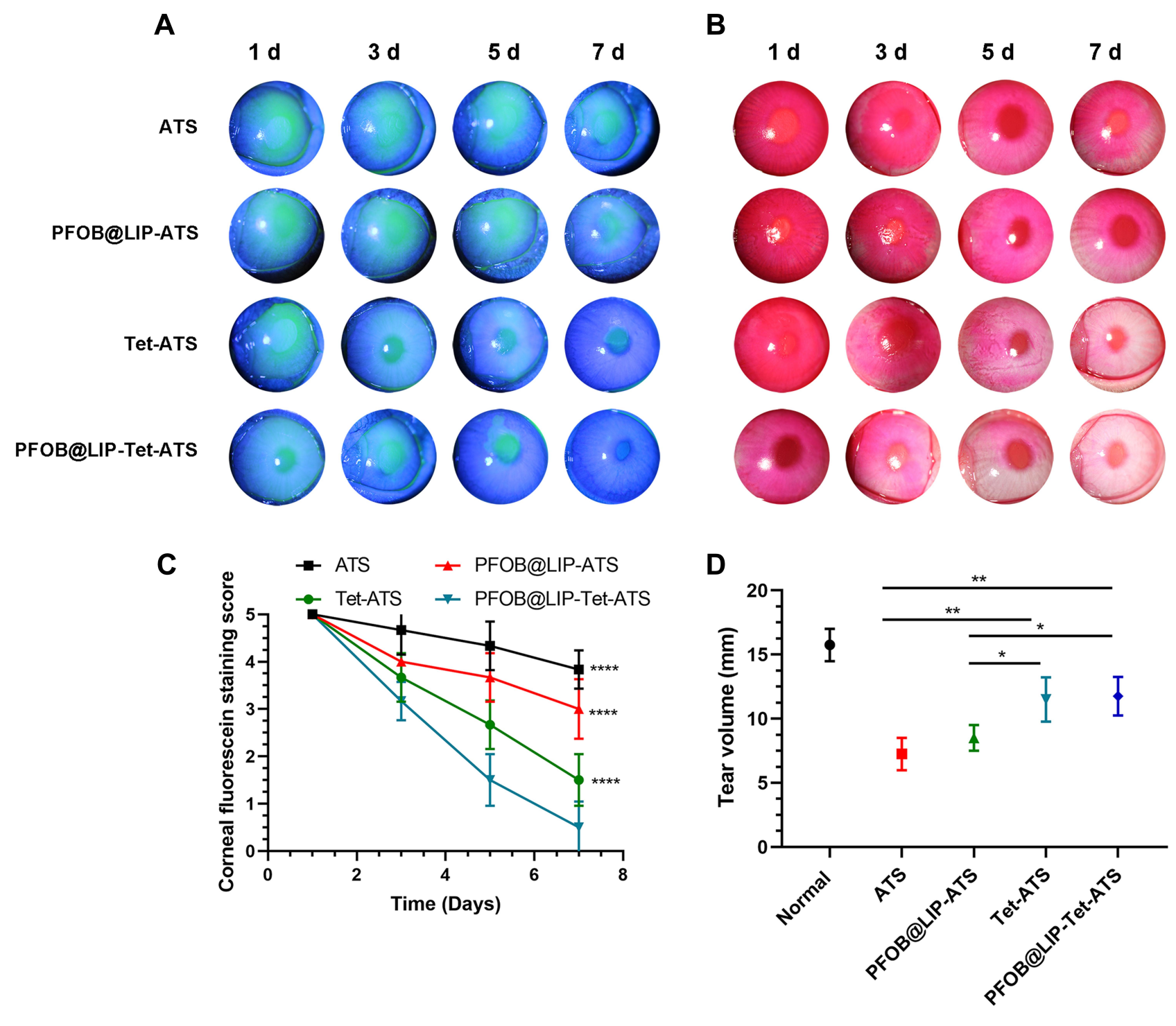

Figure 8 (A) Fluorescein staining images of rabbit cornea after respectively treated by ATS, PFOB@LIP-ATS, Tet-ATS and PFOB@LIP-Tet-ATS for one, three, five, and seven days (Tet: $0.1 \mathrm{mg} / \mathrm{mL}$ ). (B) Rose Bengal stained images of rabbit corneas after respectively being treated by ATS, PFOB@LIP -ATS, Tet-ATS and PFOB@LIP-Tet-ATS for one, three, five, and seven days (Tet: $0.1 \mathrm{mg} / \mathrm{mL}$ ). (C) Analysis of staining scores of (A and B) with PFOB@LIP-Tet-ATS serving as the control group. (D) Schirmer test results after a weeks treatment. Ordinary one-way ANOVA and two-way ANOVA were performed $(* P<0.05, * * P<0.01, * * * P<0.000 \mathrm{I})$.

the ATS,PFOB@LIP-ATS, Tet-ATS, and PFOB@LIP-Tet groups was $16.2 \pm 3.3 \mathrm{mmHg}, 12.8 \pm 2.2 \mathrm{mmHg}, 12.5 \pm 1.7$ $\mathrm{mmHg}$, and $14.8 \pm 1.7 \mathrm{mmHg}$, respectively before treatment, then corresponding eye pressure after treatment was $16.2 \pm 2.315 \mathrm{mmHg}, \quad 13.0 \pm 2.0 \mathrm{mmHg}, \quad 12.6 \pm 1.6$ $\mathrm{mmHg}$, and $15.0 \pm 2.7 \mathrm{mmHg}$, and then we prolonged therapy time to 14 days further observe the effect of PFOB@LIP-Tet-ATS formulations on eye pressure, the measured eye pressure was $14.8 \pm 1.3 \mathrm{mmHg}, 11.8 \pm 1.5$ $\mathrm{mmHg}, 10.2 \pm 0.7 \mathrm{mmHg}$, and $13.3 \pm 0.4 \mathrm{mmHg}$ (Figure 10 and 11). By analyzing the data, changes of eye pressure in the ATS and PFOB@LIP-Tet-ATS groups showed no statistical significance in the whole treatment course, while statistical difference was found between the ATS and Tet-ATS groups, for eye pressure was decreased after being treated by Tet-ATS for 14 days.

\section{Discussion}

Ocular inflammation is an important factor in occurrence and development of dry eye disease. ${ }^{8}$ Cytokines, including Il-1 $\beta$, TNF- $\alpha$, and $\mathrm{PEG}_{2}$ and VEGF, have been certified to play an important role in DED, and by inhibiting expression of those cytokines, symptoms of DED could be significantly alleviated. ${ }^{35-39}$ Traditional anti-inflammatory 
A Normal

$50 \mu \mathrm{m}$

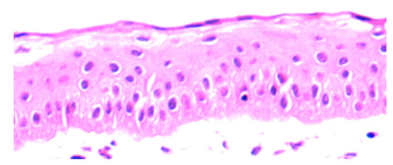

$\frac{50 \mu \mathrm{m}}{25,70 t-A T S}$

B
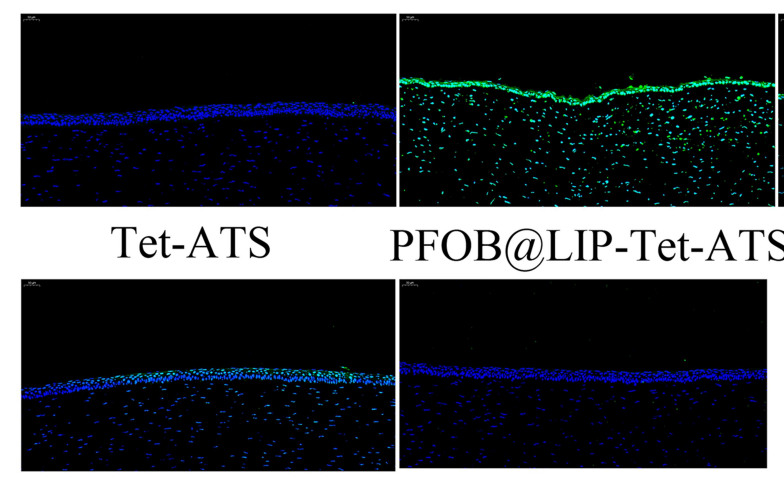

C

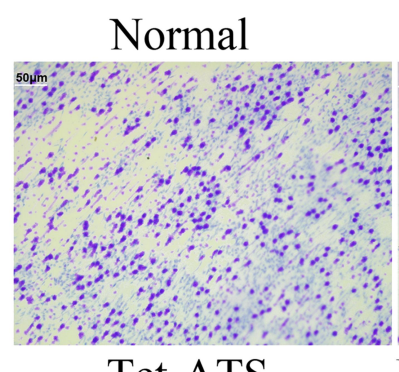

Tet-ATS

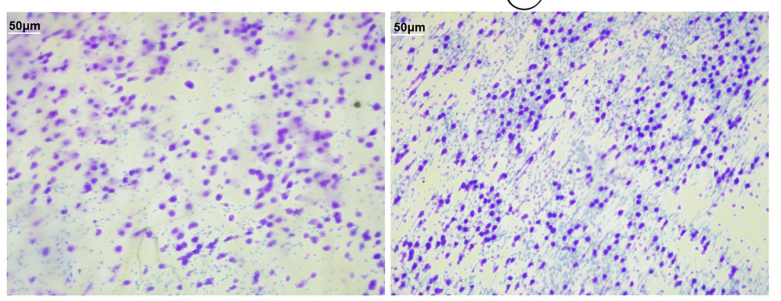

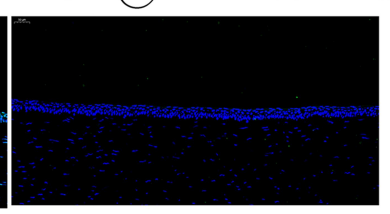

PFOB@LIP-ATS

$50 \mu \mathrm{m}$

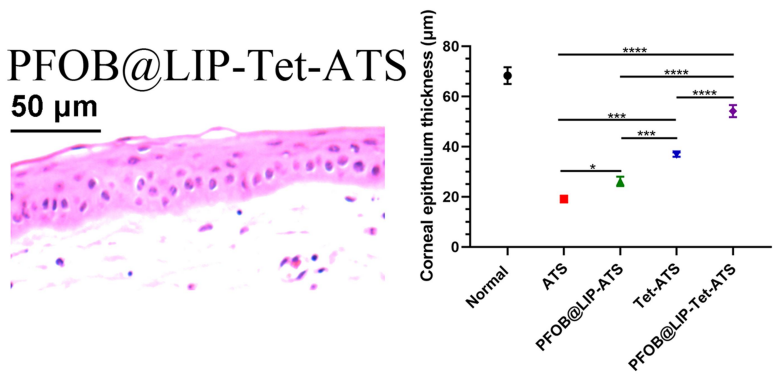

ATS

PFOB@LIP-ATS
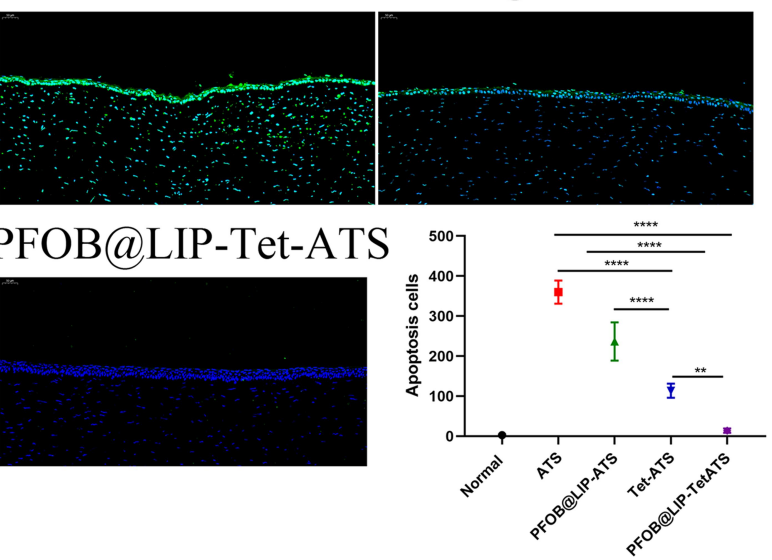

PFOB@LIP-ATS

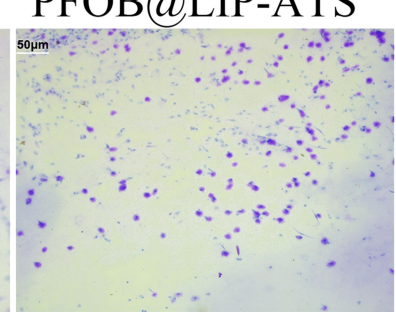

PFOB@LIP-Tet-ATS

$50 \mu \mathrm{m}$

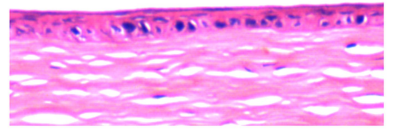




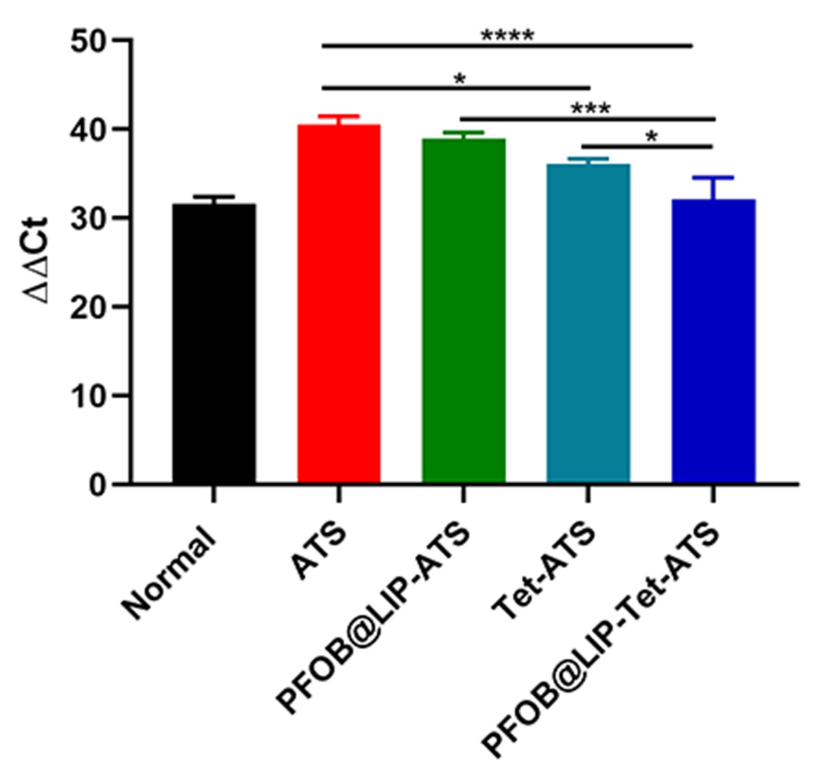

IL-1 $\beta$

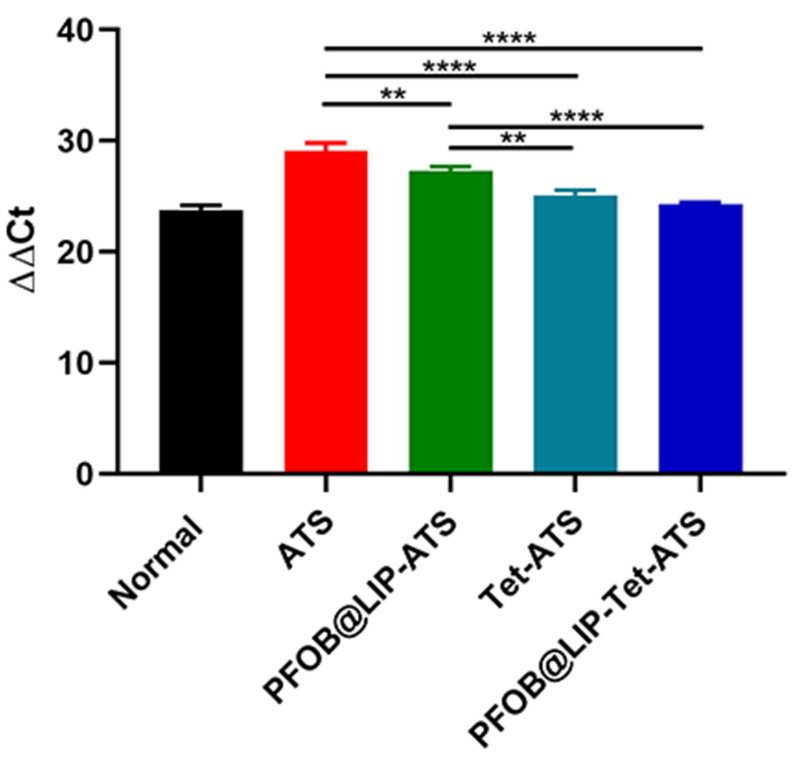

TNF- $\alpha$

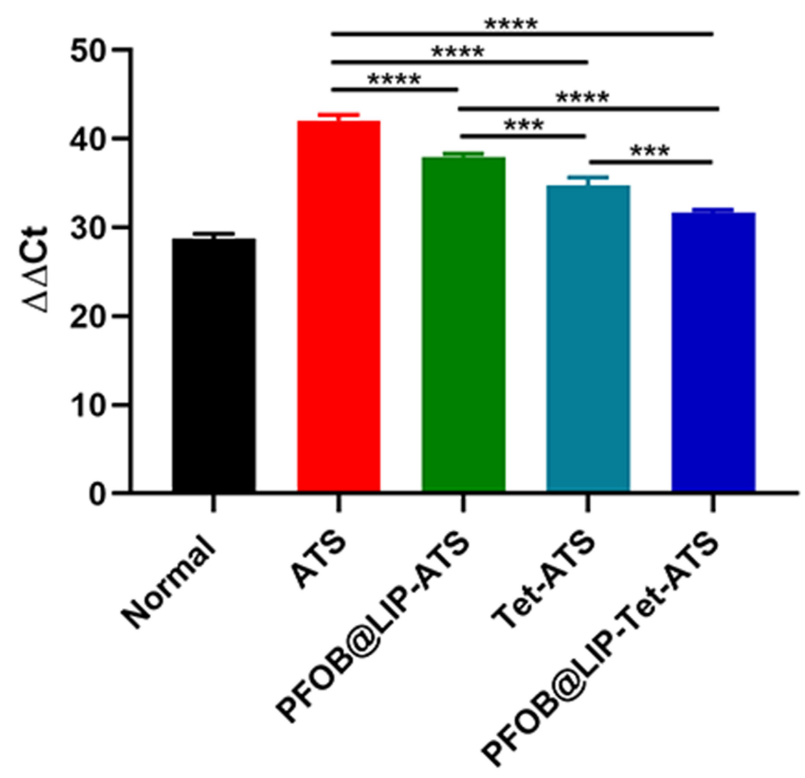

$\mathrm{PEG}_{2}$

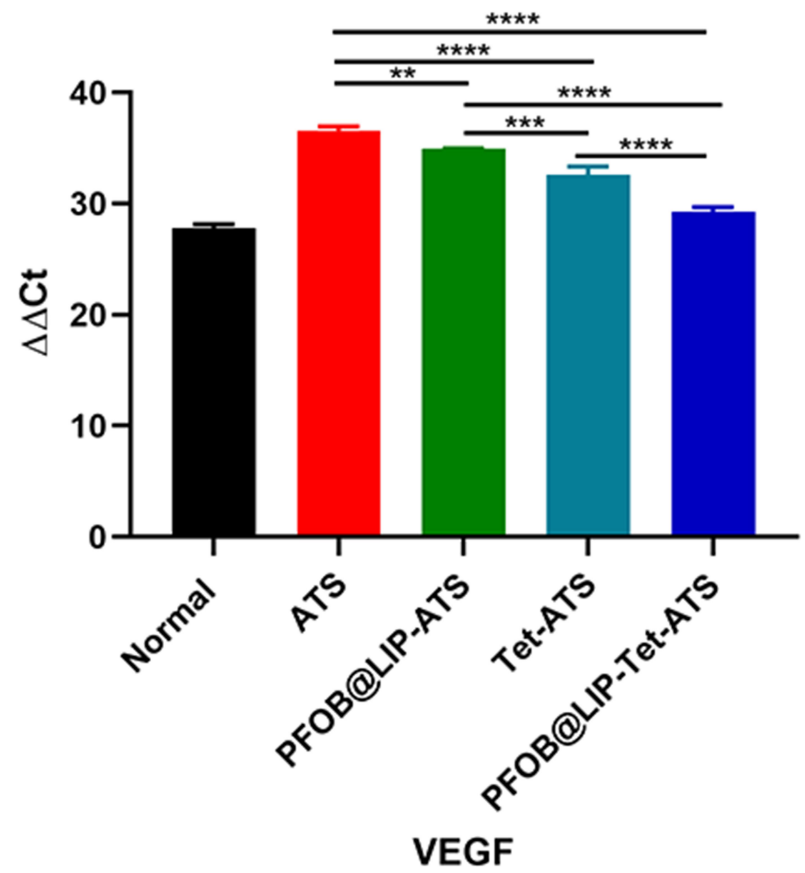

Figure 10 Translation level of gene IL-I $\beta$, PEG, VEGF, and TNF- $\alpha$ in corneas dissected from the rabbits of ATS, PFOB@LIP-ATS, Tet- ATS and PFOB@LIP-TetATS (Tet: $0.1 \mathrm{mg} / \mathrm{mL})$ group after seven days treatment. Ordinary one-way ANOVA was performed $(* P<0.05, * * P<0.01, * * * P<0.001, * * * * P<0.000 \mathrm{I})$

agents like corticosteroids would result in disastrous incidence if inappropriately applied, including intraocular hypertension and cataract, ${ }^{10}$ which narrows its use in DED therapy. Therefore, an effective anti-inflammation agent with less impact on intraocular pressure is worthy of exploration. Tet, a plant alkaloid isolated from a traditional Chinese herb, ${ }^{11}$ is initially used as an anti- inflammation agent to treat rheumatoid arthritis. It has been demonstrated that Tet could suppress the release of IL-1 $\beta$, TNF- $\alpha$, VEGF and $\mathrm{PEG}_{2}{ }^{40-43}$ and in ophthalmology, it has been studied to use Tet to cure inflammatory diseases including conjunctivitis and uveitis, ${ }^{19,22}$ what is more, the effect of Tet on eye pressure has been studied. $^{20}$ Therefore, we hypothesized that Tet could treat 
dry eye disease by inhibiting the expression of cytokines IL- $1 \beta$, TNF- $\alpha$, VEGF and PEG $_{2}$.

Liposomes as drug carriers, for plant alkaloids, ${ }^{44}$ have long been studied and their advantage of reducing toxicity and prolonging action time of the encapsulated drug has been fully used to carry drugs to treat anterior eye disease. $^{25,45}$ For low secretion of tears and tear barriers was broken in DED, it was thought conventional to settle on the ocular surface without difficulty, so we thought it was not necessary for this study to modify the liposomes to obtain better adherence and longer residence time. PFOB, a phase-change material, has been certified for the function of targeting epithelial cells and locating inflammation. ${ }^{31}$ In addition, for the preparation of liposomes in this study, PFOB could significantly increase the encapsulation efficiency of Tet (Figure S3). Here, PFOB was used as a core in the synthesis of liposomes. ATS is the baseline medicine and widely used in DED therapy, no matter the severity of the disease, so it is employed to suspend the liposomes in this study.

In this study, we firstly detected the physicochemical property of PFOB@LIP-Tet immediately after its preparation. Diameter, morphology, zeta potential, and ultraviolet absorption spectrum suggested that Tet and 1-bromoheptadecafluorooctane were successfully loaded on liposomes, with Tet inserted into the shell and PFOB serving as the core (Figure $2 \mathrm{~A}-\mathrm{C}, \mathrm{E}$ and $\mathrm{F}$ ). Then the mean size with prolonged time duration was detected to certify the stability of PFOB@LIP-Tet and results showed that it could exist stably when stored at $4^{\circ} \mathrm{C}$ (Figure 2D). Next, the standard curve of free Tet was drawn according to its ultraviolet absorbance at different concentrations (Figure $3 \mathrm{~A}$ and $\mathrm{B}$ ), and then the encapsulation efficiency and loading capacity of Tet were calculated with the help of a standard curve. The release of Tet in ATS was examined at $4^{\circ} \mathrm{C}, 25^{\circ} \mathrm{C}$, and $33^{\circ} \mathrm{C}$. Its releasing pattern at $4^{\circ} \mathrm{C}$ and $25^{\circ} \mathrm{C}$ also suggested stability of PFOB@LIP-Tet, and its controlled release performance at $33^{\circ} \mathrm{C}$ (Figure $3 \mathrm{C}$ and $\mathrm{D}$ ) combined with its encapsulation efficiency and loading capacity indicated the successful preparation of a sustainable release system.

After the controlled release system was successfully synthesized, we tested the biosafety of PFOB@LIP-Tet formulations using CCK-8 and live/dead staining. Comparing the cell viability of Tet free in solution and encapsulated in PFOB@LIP-Tet at the concentration of 10 $\mu \mathrm{g} / \mathrm{mL}$, results indicated that the cell was increased after it was loaded onto PFOB@LIP-Tet (Figure 4A). The cell viability and prevalence of green fluorescent cells showed that $5 \mu \mathrm{g} / \mathrm{mL}$ was the safe concentration for Tet, regardless free in solution or encapsulated in liposomes, whatis more, Tet becomes safer when loaded on liposomes (Figure 4A and $\mathrm{B}$ ). Then we examined the accumulations of liposomes with fluorescent tags in vitro and in vivo. In order to verify our hypothesis, its distributions respectively in normal cells and normal eyes were used as the control group. Though comparing CLSM images and analyzing FC results (Figure $5 \mathrm{~A}-\mathrm{C}$ ), the outstanding ability of inflamed SIRC cells to take in PFOB@LIP-Tet was proved, but that of normal SIRC cells was not evident. Then according to the intensity of DiR-labeled PFOB@LIP-Tet flowing out with tears, we could compare the quantity of liposomes remaining in the normal eyes and DED eyes, after analyzing the relative fluorescence intensity (Figure 6A and S1A), we could find that there were much more liposomes residing in the DED eye, and then we detected the fluorescence intensity of different eye segments dissected from the normal eyes and DED eyes, we found that the liposomes staying in DED eyes mostly assembled in the conjunctiva and cornea (Figure 6B and $\underline{\mathrm{S} 1 \mathrm{~B})}$. In addition, DiI-tagged liposomes were used to detect the penetration of PFOB@LIP-Tet in the corneal epithelium, and from the CLSM images, we could see that the corneal epithelium with DED was full of DiI fluorescence signal, and that in normal corneal epithelium there was almost none (Figure 6C). All those results demonstrated that only inflamed corneal cells take in PFOB@LIP-Tet easily, but it is hard for normal corneal epithelial cells to do that. Namely, it is possible for conventional liposomes to settle down on the DED cornea easily, which proved our assumption. What is more, tear secretions of rabbits were suppressed when anesthetized, which means that the speed of PFOB@LIP-Tet flowing out of normal eyes would be quicker when rabbits were under normal conditions. The difference of the accumulation of PFOB@LIP-Tet between in DED corneal cells and normal corneal cells, both in vitro and in vivo, also indicated that accumulation of PFOB@LIP-Tet would be decreased as the inflammation alleviated, in other words, PFOB@LIP-Tet is safer with the improvement of dry eye disease.

Then we assessed the anti-inflammation effects of PFOB@LIP-Tet formulations both in vitro and in vivo. In vitro, expressions of cytokines including VEGF, IL-1 $\beta$, TNF- $\alpha$ and $\mathrm{PEG}_{2}$ were tested both in normal SIRC cells and inflamed SIRC cells treated by PFOB@LIP-Tet 
formulations. As RT-PCR and ELISA results showed (Figure 7A and $\mathrm{B}$ ), the expressions of VEGF, IL-1 $\beta$, TNF- $\alpha$ and $\mathrm{PEG}_{2}$ were downregulated in inflamed SIRC cells after being treated by FOB@LIP-Tet formulations, especially by PFOB@LIP-Tet. Then the rates of SIRC cells surviving from inflammation was analyzed by flow cytometry after being treated by PFOB@LIP-Tet formulations. As shown in FCM results (Figure S2A and S2B), survival rates of inflamed SIRC cells were significantly increased after incubation with FOB@LIP-Tet elements for 24 and $48 \mathrm{~h}$, which was consistent with PCR and ELISA results. Next, the therapeutic effects of PFOB@LIP-Tet were evaluated relied on clinical and pathological examinations on DED models. Suspended in ATS, PFOB@LIP-Tet showed outstanding remedial function on DED while observing the stained cornea with DED at different intervals (Figure 8A and B). By compiling statistics of staining scores, statistical significance was evident (Figure 8C). The Schirmer test was also performed to detect the quantity of tear secretions of DED rabbits from all groups, and by gathering statistics, tear secretions of DED rabbits were significantly increased after being treated by PFOB@LIP-Tet-ATS (Figure 8D), but still lower than that of normal rabbits, which meant that lachrymal glands were not completely recovered. Then PAS, H\&E and TUNEL staining were performed to observe the conjunctival goblet cells, corneal epithelial thickness and apoptosis of corneal epithelial cells. From staining images, we found that goblet cell number and corneal epithelium thickness were increased while corneal epithelial cell apoptosis was decreased after treatment, especially treatment by PFOB@LIP-Tet-ATS, and the measured thickness and the counted number of apoptosis cells and goblet cells were analyzed, and statistical difference was significant (Figure 9A-C). Translations of gene VEGF, IL$1 \beta$, TNF- $\alpha$ and $\mathrm{PEG}_{2}$ in corneas were downregulated after DED rabbits were treated by PFOB@LIP-Tet-ATS elements, especially by PFOB@LIP-Tet-ATS, from which significance could be easily found (Figure 10). PCR also declared that the anti-inflammation function of PFOB@LIP-Tet was performed by inhibiting the expression of VEGF, IL-1 $\beta$, TNF- $\alpha$ and $\mathrm{PEG}_{2}$. At last, the eye pressure changes were examined before and after treatment. In order to further observe effects of liposome elements on intraocular pressure, administration time was prolonged to 14 days. By analyzing the change of eye pressure, no meaningful statistical difference was found between the ATS and PFOB@LIP-Tet-ATS groups but

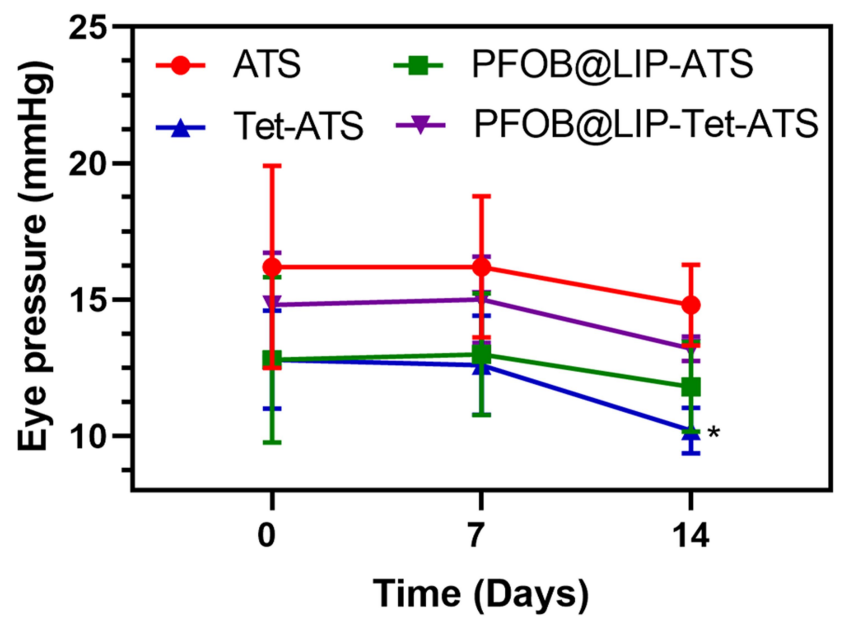

Figure I I Eye pressure of model eyes detected at 0, 7 and I4 d. Two-way ANOVA was performed for analysis with ATS group serving as the control group $(* P<0.05)$.

significance existed between the ATS and Tet-ATS groups (Figure 11), meaning that PFOB@LIP-Tet-ATS has less influence on eye pressure than Tet. To sum up, PFOB@LIP-Tet is more effective than Tet for dry eye disease treatment, but has less impact than Tet on intraocular pressure.

\section{Conclusions}

Liposome was successfully synthesized using a traditional film dispersion ultrasonic oscillation method in one-step. Tet and PFOB were loaded onto the liposome with success, with Tet inserted into shell and PFOB serving as the core of liposome. It is certified that PFOB@LIP-Tet is superior in biosafety and controlled release compared to Tet. As drug carriers, liposomes were long criticized for leakage of encapsulated molecules and disintegration automatically, ${ }^{25}$ but we coincidentally utilized those characters of liposomes to realize the release of Tet and PFOB from liposomes without exerting additional force in this study. Our assumption has been confirmed, for conventional liposome PFOB@LIP-Tet showed obvious accumulation on DED corneal epithelium. After combining with PFOB and loading onto the liposome, the antiinflammation function of Tet was increased and its impact on intraocular pressure was decreased. PFOB@LIP-Tet could effectively treat dry eye disease via anti-inflammation, which was realized by inhibiting the expression and release of VEGF, IL-1 $\beta$, TNF- $\alpha$ and $\mathrm{PEG}_{2}$, but had little impact on intraocular pressure. What is more, the role of PFOB@LIP-Tet will be gradually weakened along with the prosperity of tear film barrier and the elimination of inflammation in ocular surface. 
In addition, antioxidant action of Tet has been found, ${ }^{17}$ which we supposed also plays an important role in treatment of Tet on dry eye disease. We will verify this role of Tet and PFOB@LIP-Tet in the improvement of dry eye disease in the following study.

\section{Acknowledgments}

The authors are grateful to American Journal Experts (AJE) for their assistance with language editing. This study was support by a Key Program of Chongqing Natural Science Foundation (No. CQYC202003073).

\section{Disclosure}

The authors report no conflicts of interest in this work.

\section{References}

1. Craig JP, Nichols KK, Akpek EK, et al. TFOS DEWS II definition and classification report. Ocul Surf. 2017;15(3):276-283. doi:10.1016/j.jtos.2017.05.008

2. Qin B, Wang J, Yang Z, et al. Epidemiology of primary Sjögren's syndrome: a systematic review and meta-analysis. Ann Rheum Dis. 2015;74(11):1983-1989. doi:10.1136/annrheumdis-2014-205375

3. Fox RI. Sjogren's syndrome. Lancet. 2005;366(9482):321-331. doi:10.1016/S0140-6736(05)66990-5

4. Farrand KF, Fridman M, Stillman IÖ, Schaumberg DA. Prevalence of diagnosed dry eye disease in the United States among adults aged 18 years and older. Am J Ophthalmol. 2017;182:90-98. doi:10.1016/j. ajo.2017.06.033

5. Patel VD, Watanabe JH, Strauss JA, Dubey AT. Work productivity loss in patients with dry eye disease: an online survey. Curr Med Res Opin. 2011;27(5):1041-1048. doi:10.1185/03007995.2011.566264

6. Foulks GN, Forstot SL, Donshik PC, et al. Clinical guidelines for management of dry eye associated with Sjogren disease. Ocul Surf. 2015;13(2):118-132. doi:10.1016/j.jtos.2014.12.001

7. Jacobi C. Treatment of dry eye disease. Acta Ophthalmol. 2019;97 (S263).

8. Hessen M, Akpek EK. Dry eye: an inflammatory ocular disease. J Ophthalmic Vis Res. 2014;9(2):240-250.

9. Messmer EM. The pathophysiology, diagnosis, and treatment of dry eye disease. Dtsch Arztebl Int. 2015;112(5):71-81, 82. doi:10.3238/ arztebl.2015.0071

10. Li J, Tripathi RC, Tripathi BJ. Drug-induced ocular disorders. Drug Saf. 2008;31(2):127-141.

11. Chen KK, Chen AL The alkaloids of Han-Fang-Chi. J Biol Chem. 1935;109(2):681-685.

12. Department of Pharmacology, Wuhan Medical College and Health Department, Wuhan Textile Factory. A clinical study of the antihypertensive effect of tetrandrine. Chin Med J (Engl). 1979;92 (3): 193-198

13. Chang DM, Chang WY, Kuo SY, Chang ML. The effects of traditional antirheumatic herbal medicines on immune response cells. J Rheumatol. 1997;24(3):436-441.

14. Reist RH, Dey RD, Durham JP, Rojanasakul Y, Castranova V. Inhibition of proliferative activity of pulmonary fibroblasts by tetrandrine. Toxicol Appl Pharmacol. 1993;122(1):70-76. doi:10.1006/taap.1993.1173

15. Lee JH, Kang GH, Kim KC, et al. Tetrandrine-induced cell cycle arrest and apoptosis in A549 human lung carcinoma cells. Int J Oncol. 2002;21(6):1239-1244.
16. Shuang R, Wang M, Mao J, Zou J, Ping Y. Pharmacokinetics of 10-hydroxycamptothecin-tetrandrine liposome complexes in rat by a simple and sensitive ultra-high performance liquid chromatography with tandem mass spectrometry. J Sep Sci. 2020;43(3):569-576. doi: $10.1002 /$ jssc. 201900347

17. Shi X, Mao Y, Saffiotti U, et al. Antioxidant activity of tetrandrine and its inhibition of quartz-induced lipid peroxidation. $J$ Toxicol Environ Health. 1995;46(2):233-248. doi:10.1080/15287399509532031

18. Choi HS, Kim HS, Min KR, et al. Anti-inflammatory effects of fangchinoline and tetrandrine. $J$ Ethnopharmacol. 2000;69 (2):173-179. doi:10.1016/S0378-8741(99)00141-5

19. Hu S, Merayo-Lloves J, Zhao T, Foster CS. Comparative effectiveness and molecular pharmacological mechanisms of antiallergic agents on experimental conjunctivitis in mice. $J$ Ocul Pharmacol Ther. 1998;14(1):67-74.

20. Huang $\mathrm{P}, \mathrm{Xu} \mathrm{Y}$, Wei R, et al. Efficacy of tetrandrine on lowering intraocular pressure in animal model with ocular hypertension. J Glaucoma. 2011;20(3):183-188.

21. Du Z, Zhao W, Huang Z, Chang CK, Liu W, Liu X. Inhibition effect of tetrandrine on haze formation after Epi-LASIK surgery in rabbits. Curr Eye Res. 2011;36(8):699-705. doi:10.3109/ 02713683.2011.571359

22. Xiao J, Wu S, Wang Y, Li J, Zhang S. Inhibitory effects of tetrandrine on bovine serum albumin-induced uveitis in rabbits. $J$ Ocul Pharmacol. 1993;9(2):151-156.

23. Bangham AD, Standish MM, Watkins JC. Diffusion of univalent ions across the lamellae of swollen phospholipids. $J$ Mol Biol. 1965;13 (1):238-252. doi:10.1016/S0022-2836(65)80093-6

24. Gregoriadis G, Ryman BE. Liposomes as carriers of enzymes or drugs: a new approach to the treatment of storage diseases. Biochem J. 1971;124(5):58P. doi:10.1042/bj1240058P

25. Lasic DD. Novel applications of liposomes. Trends Biotechnol. 1998;16(7):307-321. doi:10.1016/S0167-7799(98)01220-7

26. Schaeffer HE, Krohn DL. Liposomes in topical drug delivery. Invest Ophthalmol Vis Sci. 1982;22(2):220-227.

27. Kang-Mieler JJ, Rudeen KM, Liu W, Mieler WF. Advances in ocular drug delivery systems. Eye. 2020;34(8):1371-1379. doi:10.1038/ s41433-020-0809-0

28. Monem AS, Ali FM, Ismail MW. Prolonged effect of liposomes encapsulating pilocarpine $\mathrm{HCl}$ in normal and glaucomatous rabbits. Int J Pharm. 2000;198(1):29-38. doi:10.1016/S0378-5173(99)00348-8

29. Rathod S, Deshpande SG. Design and evaluation of liposomal formulation of pilocarpine nitrate. Indian J Pharm Sci. 2010;72 (2):155-160. doi:10.4103/0250-474X.65014

30. Staffey KS, Dendi R, Brooks LA, et al. Liquid ventilation with perfluorocarbons facilitates resumption of spontaneous circulation in a swine cardiac arrest model. Resuscitation. 2008;78(1):77-84. doi:10.1016/j.resuscitation.2008.02.008

31. Obraztsov VV, Neslund GG, Kornbrust ES, Flaim SF, Woods CM. In vitro cellular effects of perfluorochemicals correlate with their lipid solubility. Am J Physiol Lung Cell Mol Physiol. 2000;278(5):L1018L1024. doi:10.1152/ajplung.2000.278.5.L1018

32. Szoka FJ, Papahadjopoulos D. Comparative properties and methods of preparation of lipid vesicles (liposomes). Annu Rev Biophys Bioeng. 1980;9(1):467-508. doi:10.1146/annurev.bb.09.060180.002343

33. Xiong C, Chen D, Liu J, et al. A rabbit dry eye model induced by topical medication of a preservative benzalkonium chloride. Invest Ophthalmol Vis Sci. 2008;49(5):1850-1856. doi:10.1167/iovs.070720

34. Bron AJ, Evans VE, Smith JA. Grading of corneal and conjunctival staining in the context of other dry eye tests. Cornea. 2003;22 (7):640-650. doi:10.1097/00003226-200310000-00008

35. Barabino S, Chen Y, Chauhan S, Dana R. Ocular surface immunity: homeostatic mechanisms and their disruption in dry eye disease. Prog Retin Eye Res. 2012;31(3):271-285. doi:10.1016/j. preteyeres.2012.02.003 
36. Luo L, Li DQ, Doshi A, Farley W, Corrales RM, Pflugfelder SC. Experimental dry eye stimulates production of inflammatory cytokines and MMP-9 and activates MAPK signaling pathways on the ocular surface. Invest Ophthalmol Vis Sci. 2004;45(12):4293-4301. doi:10.1167/iovs.03-1145

37. Solomon A, Dursun D, Liu Z, Xie Y, Macri A, Pflugfelder SC. Proand anti-inflammatory forms of interleukin-1 in the tear fluid and conjunctiva of patients with dry-eye disease. Invest Ophthalmol Vis Sci. 2001;42(10):2283-2292.

38. Li YJ, Luo LJ, Harroun SG, et al. Synergistically dual-functional nano eye-drops for simultaneous anti-inflammatory and anti-oxidative treatment of dry eye disease. Nanoscale. 2019;11 (12):5580-5594. doi:10.1039/C9NR00376B

39. Huang HY, Wang MC, Chen ZY, et al. Gelatin-epigallocatechin gallate nanoparticles with hyaluronic acid decoration as eye drops can treat rabbit dry-eye syndrome effectively via inflammatory relief. Int J Nanomedicine. 2018;13:7251-7273. doi:10.2147/IJN.S173198

40. Kang JH, Lewis DM, Castranova V, et al. Inhibitory action of tetrandrine on macrophage production of interleukin-1 (IL-1)-like activity and thymocyte proliferation. Exp Lung Res. 1992;18 (5):715-729. doi:10.3109/01902149209031703

41. Wu SJ, Ng LT. Tetrandrine inhibits proinflammatory cytokines, iNOS and COX-2 expression in human monocytic cells. Biol Pharm Bull. 2007;30(1):59-62. doi:10.1248/bpb.30.59
42. Xue Y, Wang Y, Feng DC, Xiao BG, Xu LY. Tetrandrine suppresses lipopolysaccharide-induced microglial activation by inhibiting NF-kappaB pathway. Acta Pharmacol Sin. 2008;29(2):245-251. doi:10.1111/j.1745-7254.2008.00734.x

43. Ferrante A, Seow WK, Rowan-Kelly B, Thong YH. Tetrandrine, a plant alkaloid, inhibits the production of tumour necrosis factor-alpha (cachectin) hy human monocytes. Clin Exp Immunol. 1990;80(2):232-235. doi:10.1111/j.1365-2249.1990.tb05239.x

44. Benita S, Plenecassagne JD, Cave G, Drouin D, Le Hao DP, Sincholle D. Pilocarpine hydrochloride liposomes: characterization in vitro and preliminary evaluation in vivo in rabbit eye. J Microencapsul. 1984;1 (3):203-216. doi:10.3109/02652048409049359

45. Ebrahim S, Peyman GA, Lee PJ. Applications of liposomes in ophthalmology. Surv Ophthalmol. 2005;50(2):167-182. doi:10.1016/ j.survophthal.2004.12.006
International Journal of Nanomedicine

\section{Publish your work in this journal}

The International Journal of Nanomedicine is an international, peerreviewed journal focusing on the application of nanotechnology in diagnostics, therapeutics, and drug delivery systems throughout the biomedical field. This journal is indexed on PubMed Central, MedLine, CAS, SciSearch ${ }^{\mathbb{R}}$, Current Contents ${ }^{\mathbb{B}} /$ Clinical Medicine, $^{2}$
Dovepress

Journal Citation Reports/Science Edition, EMBase, Scopus and the Elsevier Bibliographic databases. The manuscript management system is completely online and includes a very quick and fair peer-review system, which is all easy to use. Visit http://www.dovepress.com/ testimonials.php to read real quotes from published authors. 